\title{
PARP mediated chromatin unfolding is coupled to long- range enhancer activation
}

Nezha S. Benabdallah ${ }^{1,2 \#}$, Iain Williamson ${ }^{1}$, Robert S. Illingworth ${ }^{1}$, Shelagh Boyle ${ }^{1}$, Graeme R. Grimes $^{1}$, Pierre Therizols ${ }^{3}$, Wendy A. Bickmore*1

${ }^{1}$ MRC Human Genetics Unit, Institute of Genetics and Molecular Medicine, University of Edinburgh, Crewe Road, Edinburgh EH4 2XU, UK

${ }^{2}$ Edinburgh Super Resolution Imaging Consortium (ESRIC) Institute of Genetics and Molecular Medicine, University of Edinburgh, Crewe Road, Edinburgh EH4 2XU, UK

${ }^{3}$ UMR INSERM 944, CNRS 7212, Bâtiment Jean Bernard, Hôpital Saint Louis, Paris, France

\#Current address: EMBL Heidelberg, Meyerhofstrasse 1, 69117 Heidelberg, Germany

*Correspondence to:

W.A.B: MRC Human Genetics Unit, IGMM, Crewe Road, Edinburgh EH4 2XU, UK

Tel: +441316518570

Email: Wendy.Bickmore@igmm.ed.ac.uk

Running title: Chromosome puffing and long-range gene activation 


\begin{abstract}
Enhancers are critical regulators of gene expression and can be located far from their target gene. It is widely assumed that mechanisms of enhancer action involve reorganization of three-dimensional chromatin architecture, but this is poorly understood. Here we identify a novel mechanism of longrange enhancer associated chromatin reorganization. At the Sonic hedgehog $(S h h)$ locus we observe large-scale decompaction of chromatin between Shh and its brain enhancers in neural progenitor cells. We show that the chromatin unfolding is dependent on activation of the enhancers, not the promoter, is impeded by chromatin-bound proteins located between the enhancer and promoter, and is mediated by the recruitment of Poly (ADP-Ribose) Polymerase 1. We suggest that large-scale chromatin decompaction, analogous to the inducible puffs in Drosophila polytene chromosomes, represents a new mechanism of chromatin reorganization coupled to long-range gene activation from mammalian enhancers and that seems incompatible with a chromatin-looping model of enhancer-promoter communication
\end{abstract}

\title{
Keywords
}

chromatin compaction, chromosome puff, enhancer, PARP, poly(ADP-ribosyl)ation, sonic hedgehog, Tal-effector. 


\section{Introduction}

Enhancers are cis-regulatory sequences, often located within the non-coding portion of the genome, which function to tightly regulate spatial and temporal gene expression in development and physiology. Enhancers can operate when located proximal to, or very distant (100s to $1000 \mathrm{~s}$ of $\mathrm{kb}$ ) from, their target gene (Vernimmen and Bickmore, 2015). Well established molecular signatures of functional enhancers include; clustered sequence-specific transcription factor binding sites and DNaseI hypersensitive sites (DHS), specific histone modifications e.g. H3K4me1 and acetylation of specific lysine residues on histone H3 (H3K27ac, H3K64ac, H3K122ac) and H4 (H4K16ac) and, in some cases, eRNA transcription (Kim et al., 2010; Pradeepa et al., 2016; Shlyueva et al., 2014; Taylor et al., 2013). However, less is known about the mechanisms by which enhancers communicate with, and control the expression of, their target gene promoter(s).

For proximal enhancers, it has been proposed that activation signals nucleated by bound transcription factors (TFs) then spread or move towards the target gene, by reorganising or modifying the intervening chromatin (Benabdallah and Bickmore, 2015; Engel et al., 2008; Hatzis and Talianidis, 2002; Wang et al., 2005; Zhao and Dean, 2004; Zhu et al., 2007). These 'tracking' or 'facilitated-tracking' models are compatible with enhancers located in the vicinity of their target promoter, but have been considered unlikely as a mechanism for more distal enhancers. For very long-range regulation, direct communication between the enhancer and the promoter is thought to occur through interaction of protein complexes bound at both sites, with looping-out of the intervening chromatin. Chromatin 'looping' has best been illustrated for interactions between the $\beta$ globin gene and its locus control region (LCR): enhancer-promoter interactions have been detected by chromosome conformation capture (3C) methods (Carter et al., 2002; Tolhuis et al., 2002) and experimentally forced enhancer-promoter chromatin looping contributes to transcriptional activation (Bartman et al., 2016; Deng et al., 2012, Deng et al., 2014) . Fluorescence in situ hybridisation (FISH) has also been used to visualise the spatial juxtaposition of a target gene $(S h h)$ with its distant $(1 \mathrm{Mb})$ limb enhancer, with a looping-out of the intervening chromatin, specifically in Shh expressing tissues of the developing limb bud (Williamson et al., 2016). A general compaction of the chromatin fibre between enhancer and promoter, rather than a discrete loop, has also been suggested (Williamson et al., 2012, 2014) and this may facilitate factors recruited at enhancers finding their promoter-proximal binding sites through diffusional mechanisms (Benabdallah and Bickmore, 2015). However, to date, no other specific chromatin conformation has been demonstrated to contribute to long-range gene regulation from enhancers.

The sonic hedgehog morphogen (Shh) governs the growth and patterning of many tissues during development. The precise spatial and temporal control of Shh expression is regulated by tissuespecific enhancers located; within the introns of the gene, upstream of the $S h h$ transcription start site 
(TSS) in a large $(750 \mathrm{~kb})$ gene desert, and within genes at the far end of the gene desert (Anderson and Hill. 2014). Shh expression is important for several aspects of brain development. Shh-BrainEnhancers-5 (SBE5), SBE2/3, SBE4 and SBE6 have been demonstrated to drive expression in the midbrain and anterior domains of the developing brain and are located 780, 450, 350 and $100 \mathrm{~kb}$ upstream of the Shh TSS, respectively (Jeong, 2006; Benabdallah et al., 2016; Yao et al., 2016). As distal enhancers, the SBE elements might be expected to loop into spatial proximity of Shh during its activation in neural progenitors cells (NPCs). However, here we show that induction of Shh expression in NPCs, or by synthetic enhancer activation in mouse embryonic stem cells (ESCs) does not lead to detectable co-localisation between Shh and SBE6, SBE4, or SBE2/3. Rather, we show that enhancer activation leads to an unfolding of chromatin between Shh and SBE4/SBE6 that appears to be mediated by the recruitment and activity of Poly (ADP-Ribose) Polymerase 1. 


\section{Results}

\section{Increased nuclear separation of Shh and Shh-Brain-Enhancers upon neural differentiation}

To analyse the spatial relationship of Shh with its known brain enhancers in the nucleus we differentiated 46c ESCs (Ying et al., 2003) into NPCs. Efficient differentiation was monitored through Sox1-GFP fluorescence (Benabdallah et al., 2016).

As the known Shh-Brain-Enhancers SBE5, SBE2/3, SBE4 and SBE6 are located 780, 450, 350 and $100 \mathrm{~kb}$ upstream of $S h$, respectively (Figure 1A), the favoured mechanism by which these enhancers control Shh would involve a physical looping between them and the Shh promoter. To test this we used super-resolution microscopy, in conjunction with 3D fluorescence in situ hybridisation (3D-FISH), to visualise the spatial proximity of the enhancers and Shh before and after neural differentiation (Williamson et al., 2016). The squared distances between two FISH probes typically have a linear relationship to the genomic distance that separates them (Gilbert et al., 2004; van den Engh et al., 1992), but is also influenced by chromatin folding (Eskeland et al., 2010; Williamson et al., 2014). Consistent with enhancer-promoter chromosome looping, we have previously demonstrated that spatial juxtaposition of Shh and it ZRS limb enhancer, with displacement of an intervening genomic region, is restricted to the time and place of Shh expression in the developing limb (Williamson et al., 2016). If chromosome looping also occurs between the brain enhancers and Shh upon neuronal activation we anticipated that hybridisation signals for the SBE distal enhancers would display a higher frequency of co-localisation with $S h$ (inter-probe distances $\leq 0.2 \mu \mathrm{m}$ ), and shorter average inter-probe distances, in NPCs as compared with undifferentiated ESCs.

We performed 3D FISH on 46c ESCs that do not express Shh, and on NPCs obtained after seven days of differentiation, when Shh is expressed (Benabdallah et al., 2016) and we imaged the slides by 3D-Structured Illumination Microscopy (3D-SIM). Surprisingly, upon Shh activation there was a significant increase in inter-probe distances between Shh and both the SBE6 and SBE4, located 100 and $350 \mathrm{~kb} \mathrm{5}$ ' of Shh respectively (Figures 1B and 1C). Inter-probe distances between Shh and the more distant SBE2/3 or ZRS were not significantly changed, nor were those to a control probe (CTRL) located $340 \mathrm{~kb}$ downstream of $S h h$ and not within the $S h h$ regulatory region (Figures 1A and 1B, Table S1). This suggests that a large-scale chromatin unfolding occurs upon Shh neural induction and that this is limited to the region $300 \mathrm{~kb} 5^{\prime}$ of the Shh TSS. It is noteworthy that, within this $300 \mathrm{~kb}$ region, the most prominent peaks of $\mathrm{H} 3 \mathrm{~K} 3 \mathrm{me} 1$ and $\mathrm{H} 3 \mathrm{~K} 27 \mathrm{ac}$ gained during this NPC differentiation programme occur at SBE6, and that SBE6 is required for full induction of Shh during this differentiation programme (Benabdallah et al., 2016). 
bioRxiv preprint doi: https://doi.org/10.1101/155325; this version posted June 25, 2017. The copyright holder for this preprint (which was not certified by peer review) is the author/funder, who has granted bioRxiv a license to display the preprint in perpetuity. It is made

A available under aCC-BY-NC-ND 4.0 International license.

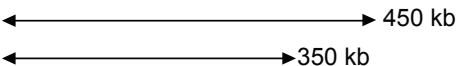

$350 \mathrm{~kb}$

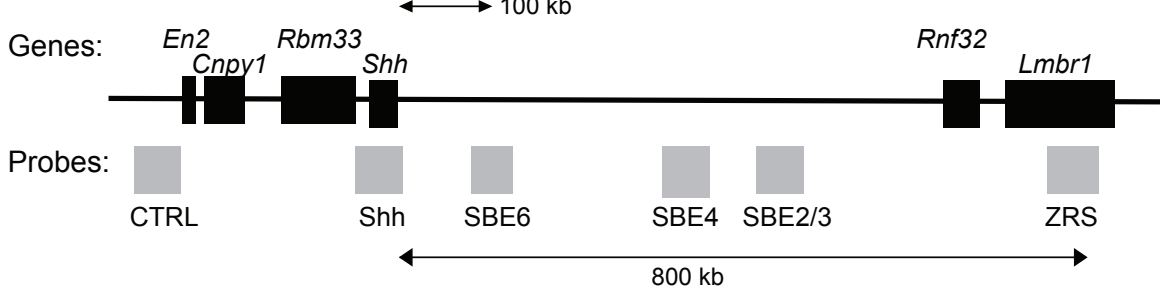

B

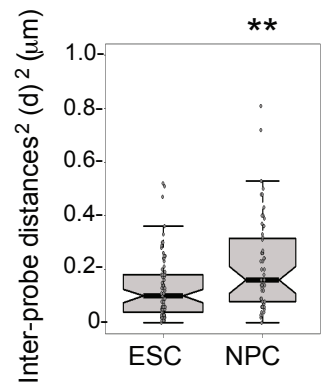

[Shh_SBE6]

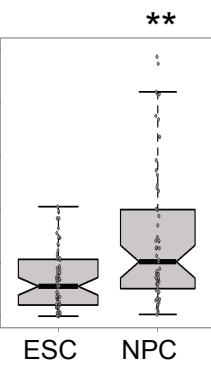

[Shh_SBE4]

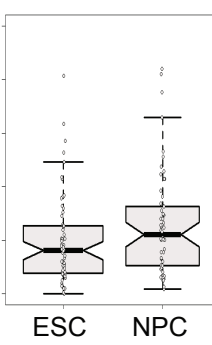

[Shh_SBE2]

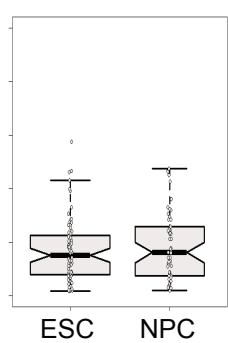

[Shh_ZRS]

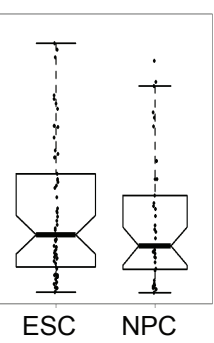

[Shh_CTRL]
C
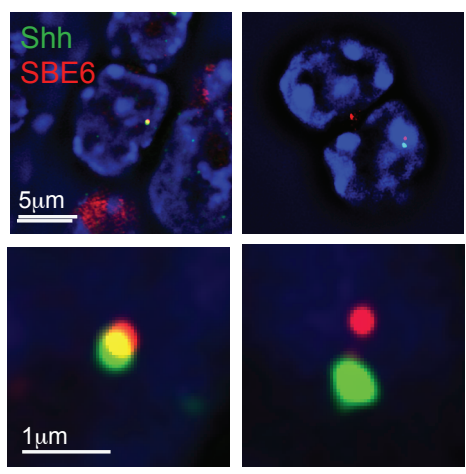

D

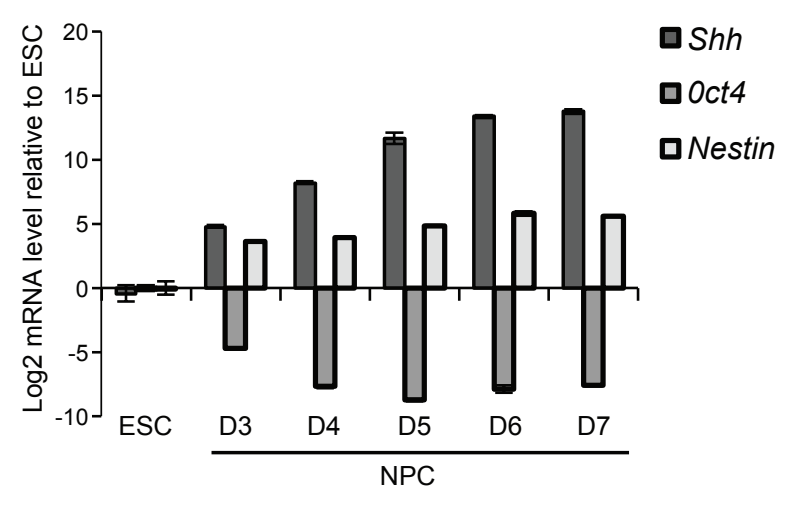

$\mathbf{F}$

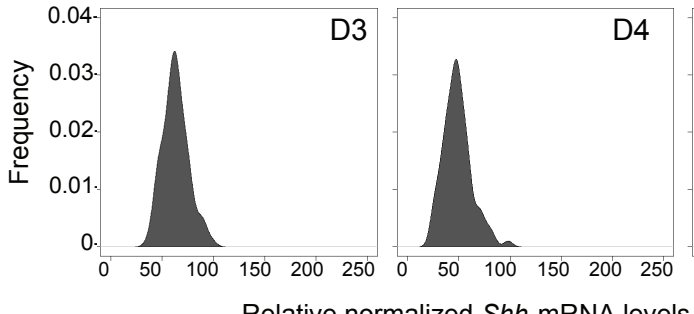

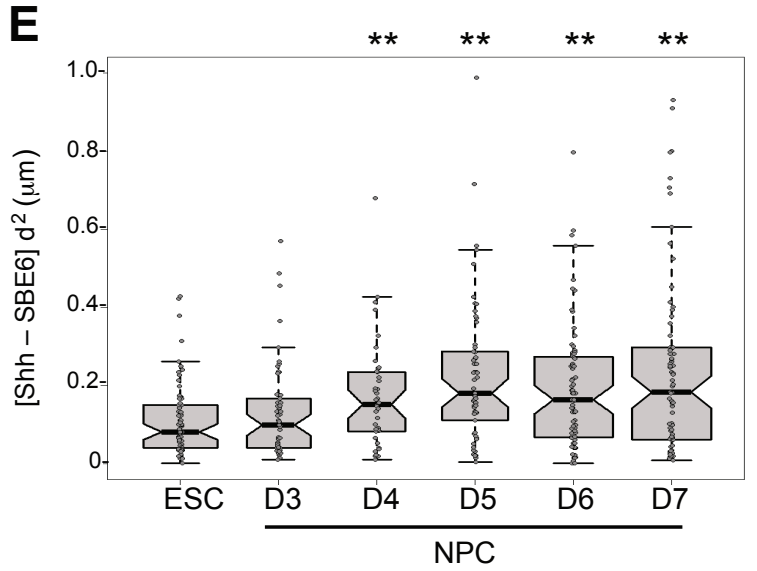

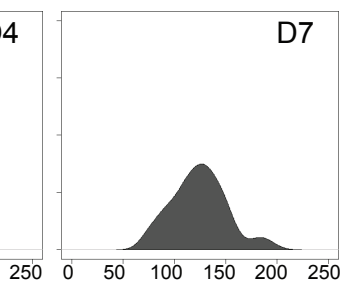

G

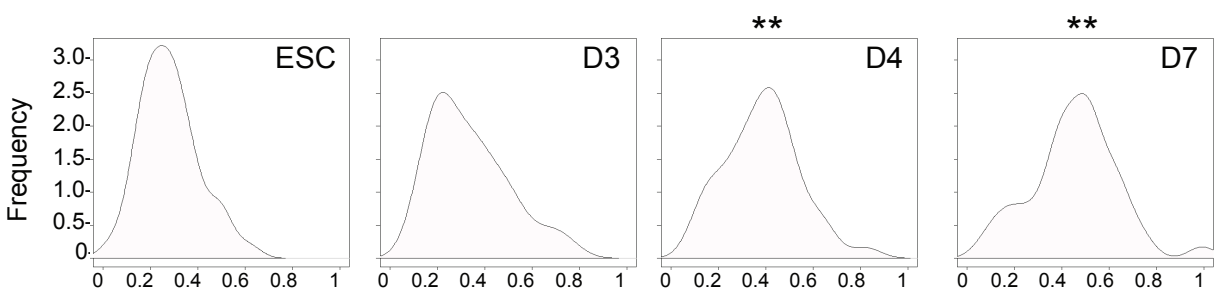

[Shh - SBE6] distances $\mathrm{d}(\mu \mathrm{m})$

\section{Figure 1. Shh-Brain-Enhancer chromatin decompaction during neuronal differentiation}

A) Map of Shk regulatory domain showing the genes (black boxes) and fosmid FISH probes (grey boxes). B) Boxplots showing the distribution of squared interprobe distances $\left(\mathrm{d}^{2}\right)$ in $\mu \mathrm{m}$ between Shh and SBE6, SBE4, SBE2/3, ZRS and CTRL probes in the nuclei of ESCs and NPCs. Box indicates interquartile range of the median ( 25 to 75 percentile) with the notch displaying a $95 \%$ confidence interval around the median. ${ }^{* *}$ p $<0.01$. C) $3 \mathrm{D}$-SIM image illustrating Shh-SBE6 separation in NPCs after seven days of differentiation from ESCs. Scales bars are $5 \mu \mathrm{m}$ (top) and $1 \mu \mathrm{m}$ (bottom). D) Shh Oct4 and $X e s t i n$ expression assayed by aRT-PCR during a time course of NPC differentiation. Graph shows mean ( \pm SEM) $\log 2$ mRNA levels relative to Gapdh and normalized to the level in ESC for one biological replicate (three technical replicates). E) Boxplots showing Shh-SBE6 squared interprobe distances in cell populations corresponding to the expression data in D. F) Kernel density plots showing Shb mRNA expression of single NPCs relative to Gapdh and normalised to expression in ESC. G) Kernel density plots showing the distribution of Shh-SBE6 FISH distances ( $\mu$ m) in undifferentiated ESCs and at days 3 , 4 and 7 (D3, D4, D7) of differentiation. Density is an arbitrary unit based on the frequency of the occurrence, and the total counts and the size of the population i.e. the binning of the data. Statistical data relating to FISH data from this figure and replicate experiments are in Table S1. 
The increased separation between Shh and SBE6/SBE4 upon Shh induction does not seem compatible with the formation of a chromatin loop between Shh and these two neural enhancers. To assess if 'looping' occurs at an earlier time point, we analyzed Shh expression at earlier stages during the NPC differentiation time course (days 3 to 7). Shh expression initiated on day 3 (D3) and increased steadily until D6 or D7 (Figure 1D). In all replicate experiments, Shh-SBE6 nuclear distances were significantly increased from D4 onwards (Figure 1E). Though Shh-SBE6 distances were somewhat increased at D3 this did not reach statistical significance in this experiment, but in other replicates, there was a significant Shh-SBE6 distance increase by D3 (Figure S1A). These data support the notion that no stable chromatin loop structures exist between SBE6 and Shh throughout this neural differentiation programme (Table S1).

To determine whether Shh activation is coupled with the observed increased promoterenhancer separation across the cell population, or whether there is a sub-population of NPCs that express $S h h$ at high levels with a looped chromatin conformation (short inter-probe distances) that are obscured in the whole population, we performed single cell qRT-PCR on cells at D3, D4 and D7 of NPC differentiation. These data show that in most cells of the population there is increased Shh expression at D3 and D4, (Figures 1F \& S1B), and even higher levels of Shh expression by D7, consistent with the cell population averaged expression data (Figure 1D). For the same cell populations, Shh - SBE6 inter-probe distances start to increase at D3 and shift homogenously towards greater distances at D4 and D7 (Figures 1G), mirroring the population wide increase in Shh expression. Across this time course, there was a corresponding decrease in the frequency of alleles with Shh-SBE6 inter-probe distances $(\leq 200 \mathrm{~nm})$ that we would consider compatible with enhancerpromoter juxtaposition (Figures 1G and S1C) (Williamson et al., 2016).

To show that 3D FISH analysis is capable of detecting a chromosome loop in ESCs, we created an artificial Shh-SBE interaction. Targeted tethering (using zinc fingers) of the selfassociation domain (SA) of LIM domain-binding protein 1 (LDB1) has been used previously to force a chromatin loop at the $\beta$-globin locus (Bartman et al., 2016; Deng et al., 2012, 2014). Using a similar approach, but employing transcription activator-like effector (Tale) proteins to direct site-specific binding (Therizols et al., 2014), we tethered the LBD1 SA to the Shh promoter (tShh-LDB1) and to either SBE6 or SBE2 (tSBE6-LDB1 and tSBE2-LDB1) in ESCs (Figure S1D). 3D FISH revealed dramatically increased enhancer-promoter co-localization $(\leq 200 \mathrm{~nm})$ upon tShh-LDB1 and tSBE6/tSBE2-LDB1 co-transfection (Figure S1E and S1F). Four-color 3D-FISH, confirmed that a chromatin conformation consistent with a loop, and not simply chromatin compaction, was formed upon Tale-LDB1 expression (Figures S1G and H \& Table S2). We conclude that 3D FISH is able to detect a chromatin loop in ESCs, albeit an artificially constructed one. 
bioRxiv preprint doi: https://doi.org/10.1101/155325; this version posted June 25,2017 . The copyright holder for this preprint (which was not certified by peer review) is the author/funder, who has granted bioRxiv a license to display the preprint in perpetuity. It is made available under aCC-BY-NC-ND 4.0 International license.

\section{Shh-SBE6 chromosome unfolding requires SBE6 and occurs in vivo}

We have shown previously that SBE6 is involved in the proper induction of Shh expression during NPC differentiation, and that there is a prominent gain of H3K4me1 and H3K27ac at this regulatory element during differentiation to Sox1+ve NPCs (Benabdallah et al., 2016). FISH showed that the increased Shh-SBE6 inter-probe distances are abolished in NPCs derived from SBE6 ${ }^{-/}$ESCs (Figure 2A). This demonstrates that chromatin unfolding across the $100 \mathrm{~kb} 5$, of Shh during NPC differentiation is dependent on SBE6.

Mouse transgenic assays indicate that SBE6 is active in brain development and in the neural tube (Benabdallah et al., 2016). Shh is expressed specifically in ventral regions of the neural tube - in the floorplate and notochord (Jeong et al., 2006) (Figure 2B) and SBE6 drives floorplate expression in a reporter assay. To assess if chromatin unfolding occurs in vivo, we used FISH to examine Shh-SBE6 inter-probe distances in sections through the neural tube of an E10.5 embryo. Shh-SBE6 distances were greater in nuclei from the floorplate region than in dorsal neural tube cells (Figure 2C), suggesting that our ex vivo analysis reflects a long-range chromatin reorganisation 5' of Shh that also occurs in vivo during neurogenesis.

To determine if other, as yet unidentified, cis-regulatory elements interact with the Shh promoter during the differentiation of ESCs to NPCs, we used Chromosome Conformation Capture Carbon Copy (5C) to assay cross-linked ligation frequencies across the Shh regulatory domain. Consistent with published Hi-C data from ESCs (Smallwood and Ren, 2013), and 5C data from E11.5 embryos (Williamson et al., 2016), 5C revealed that in both ESCs and NPCs all of the SBEs are contained in a topologically associated domain (TAD) that extends from downstream of Shh to downstream of Nom1 (Figure S2A). Comparison of 5C data from ESCs and NPCs revealed no evidence for a gain of specific interactions in NPCs that might indicate the formation of a 'loop' between Shh and its neural enhancers (Figures 2D \& S2B).

\section{SBE, and not direct Shh promoter, activation promotes chromatin unfolding.}

Supercoiling associated with transcription is known to decondense large chromatin domains (Matsumoto and Hirose, 2004; Naughton et al., 2013), therefore the chromatin unfolding we observe during NPC differentiation could occur as a passive consequence of Shh transcription. To determine if this is the case, or if chromatin unfolding depends on Shh Brain-Enhancer activation, we designed an enhancer bypass experiment, fusing a Tal effector targeted to the Shh promoter (tShh) to four repeats of the small viral acidic protein Vp16 (Vp64) that can strongly activate gene expression (Zhang et al., 2011) (Figure 3A), including in ESCs (Therizols et al., 2014). Expression of tShh-Vp64 in ESCs led to the activation of $S h h$ expression to levels similar to those seen in differentiated NPCs (Figure 3B), 
bioRxiv preprint doi: https://doi.org/10.1101/155325; this version posted June 25, 2017. The copyright holder for this preprint (which was not certified by peer review) is the author/funder, who has granted bioRxiv a license to display the preprint in perpetuity. It is made available under aCC-BY-NC-ND 4.0 International license.

A

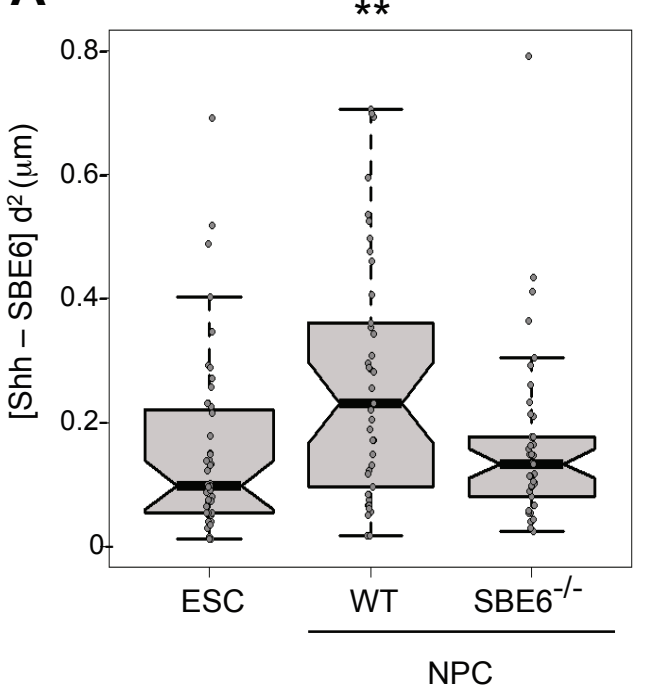

B

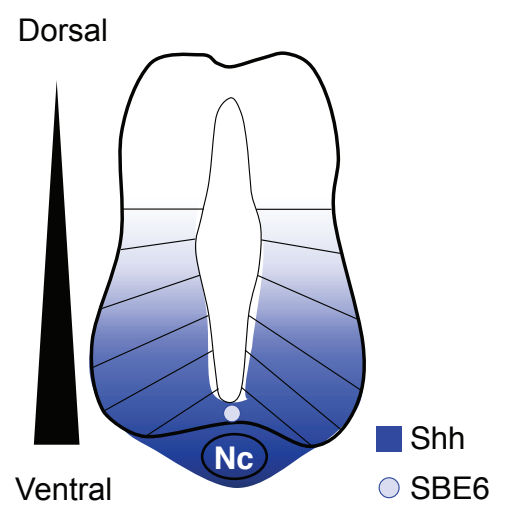

C

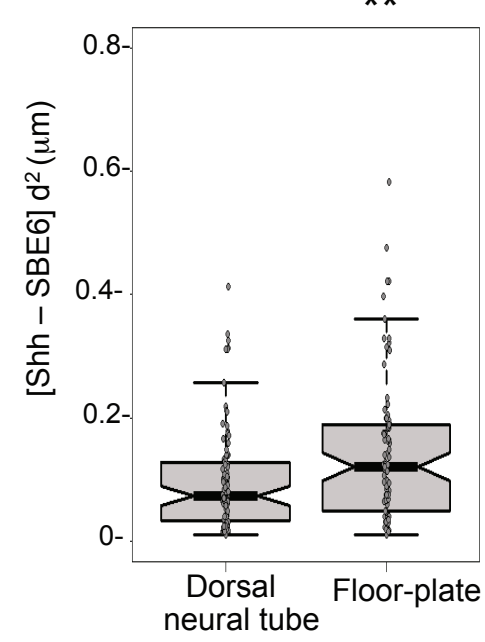

D

ESC

0

0.21

Binning $5 \mathrm{~kb}$ Smooth int. 3

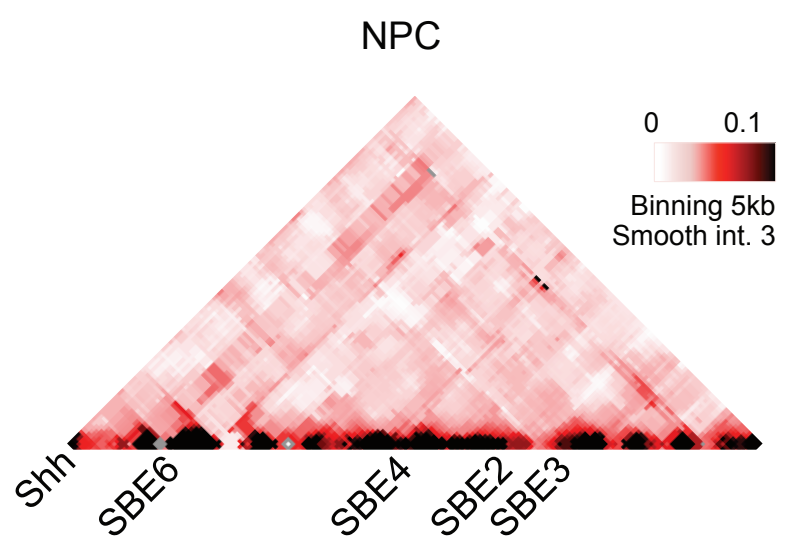

Figure 2. Chromatin unfolding is SBE6 dependent and occurs in vivo

A) Boxplots showing the distribution of squared interprobe distances $(\mu \mathrm{m})$ between Shh and SBE6 in ESCs and in wild-type NPCs as well as in NPCs derived from SBE6.1 ${ }^{-/}$cells. ${ }^{* *} p_{-}<0.01$. B) Schematic of a transverse section through the neural tube with a gradient of Shh emanating from ventral Shh expressing cells in the notochord ( $\mathrm{Nc}$ ) and the floor-plate, where SBE6 activity is also detected (Benabdallah et al., 2016). C) Shh-SBE6 inter-probe distances as in (A) but for FISH data from E10.5 dorsal neural tube and ventral floor-plate cells. ${ }^{* *} p<0.01$ for this biological replicate. For two other biological replicates $\mathrm{p}=0.002$ and $\mathrm{p}<0.001$. D) $5 \mathrm{C}$ heat-maps of the Shh regulatory region (mm9, chr5:28750000-29450000) from ESCs and NPCs with $5 \mathrm{~kb}$ binning and smoothing with the median of 3 surrounding interactions frequencies. 
bioRxiv preprint doi: https://doi.org/10.1101/155325; this version posted June 25, 2017. The copyright holder for this preprint (which was not certified by peer review) is the author/funder, who has granted bioRxiv a license to display the preprint in perpetuity. It is made available under aCC-BY-NC-ND 4.0 International license.

A

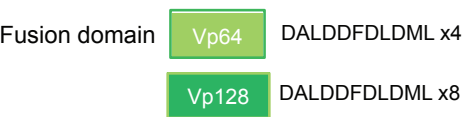

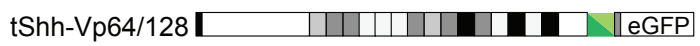

tSBE6-Vp64/128

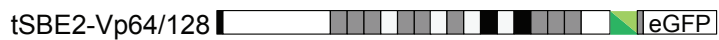

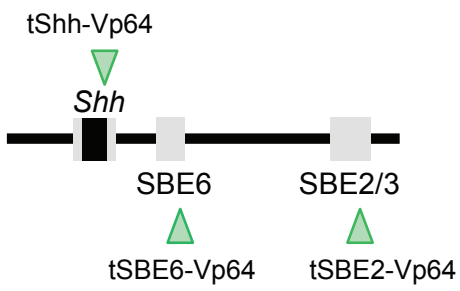

B

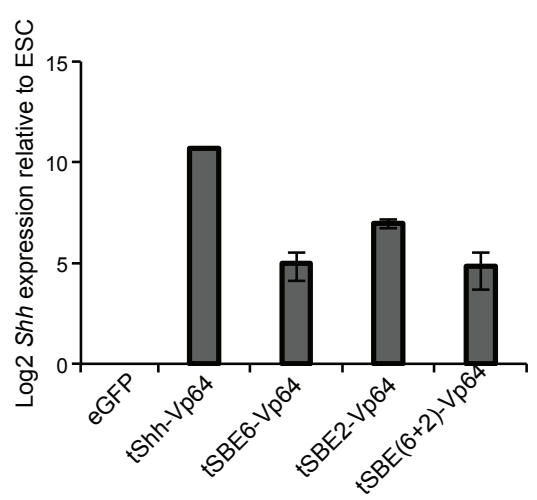

D

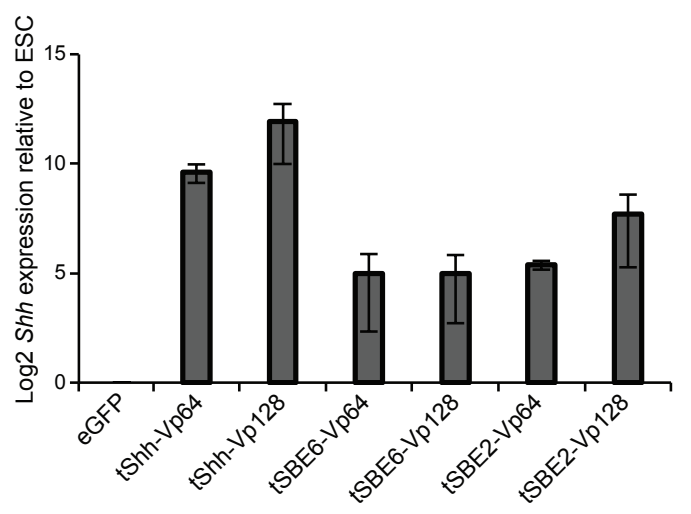

C
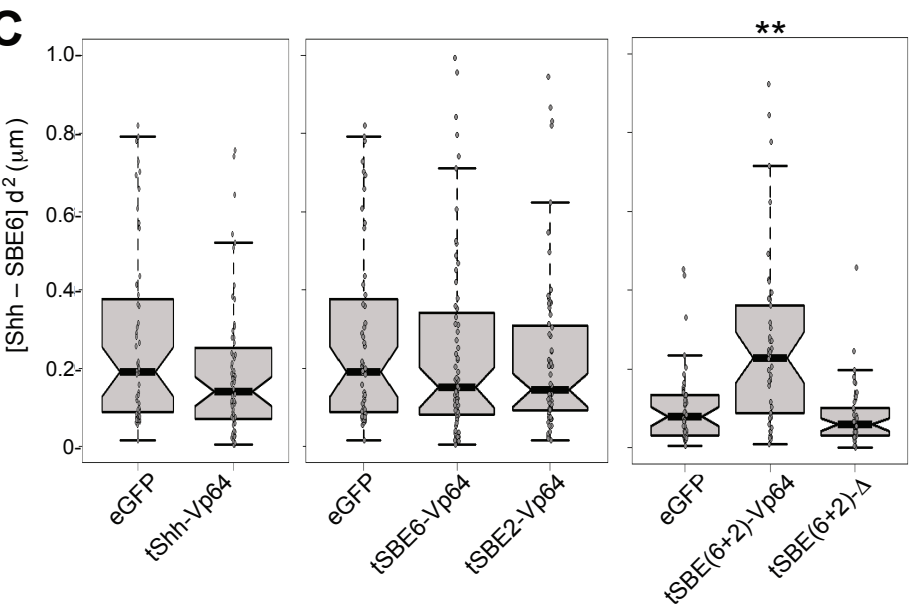

E

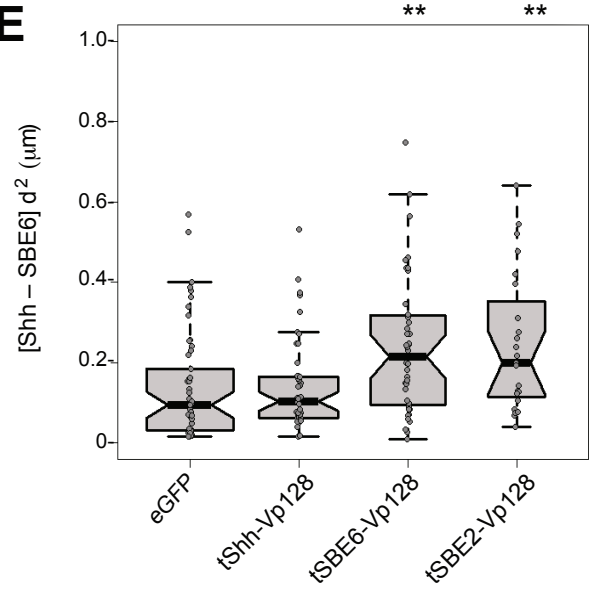

$\mathbf{F}$

ESC

tSBE6-Vp64

tSBE2-Vp64

tSBE(6+2)-Vp6.

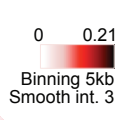

$0 \quad 0.21$
Binning 5kb
Smooth int. 3

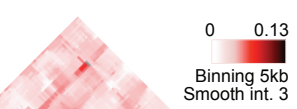

0.17

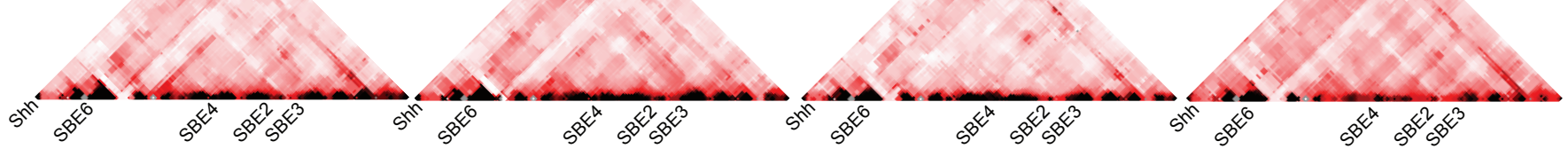

Figure 3. Synthetic activation of Shh and chromatin unfolding using Tale-Vp16.

A) Tale-Vp64 and Tales-Vp128 constructs targeting the Shh promoter (tShh), SEB6 or SBE2. B) Log2 mRNA levels of Shh, relative to Gapdh, assayed by gRT-PCR after Tale-Vp64 expression in ESCs. Data show mean ( \pm SEM) of three biological replicates normalized to ESCs expressing a control eGEP, C) Boxplots representing Shh-SBE6 squared interprobe distances $(\mu \mathrm{m})$ in ESCs expressing; control eGEE, Tale-Vp64 fusions targeting Shh promoter (tShb), SBE6 (tSBE6-Vp64), SBE2 (tSBE2-Vp64), or both SBE6 and SBE2 (tSBE6+2)-Vp64, or a Tal with no fusion protein (tSBE6+2)- $\Delta$. ${ }^{* *}$ p $<0.01$. D) As in (B) but for both Tale-Vp64 and Tale-Vp128 fusions. E) As in (C) but for Tale-Vp128 fusions. F) 5C heat-maps of the Shh regulatory region (chr5:2875000229450000 ) with $5 \mathrm{~kb}$ binning and smoothing with the median of 3 surrounding interactions frequencies for ESCs and for ESCs expressing Tale-Vp64 fusions targeting SBE6, SBE2 or both SBE6 and SBE2. Statistical analysis for FISH data from this figure and replicate experiments are in Table S3. 
but without perturbing markers of plurpotency or neuronal differentiation (Figure S3A). However, this synthetic activation of Shh in ESCs did not lead to the increased Shh-SBE6 inter-probe distances observed during NPC differentiation (Figure 3C). Therefore, chromatin unfolding upstream of Shh is not simply a consequence of activating Shh expression.

Recruiting Vp64 to SBE2 or SBE6 individually, or in combination, through tSBE6-Vp64 and tSBE2-Vp64 also induced Shh expression, albeit less marked compared to direct Vp64 recruitment to the $S h h$ promoter (Figure 3B). Shh activation by Tale-Vp64 recruitment to either SBE2 or SBE6 alone did not lead to increased Shh-SBE6 inter-probe distances (Figure 3C and Table S3). However, simultaneously co-activating SBE6 and SBE2, by co-transfecting both tSBE6-Vp64 and tSBE2-Vp64 (tSBE(6+2)-Vp64), led to significant distance increases between Shh and SBE6 (Figure 3C). This was specific to Vp64 activity as recruiting Tales without a fusion domain $(\operatorname{tSBE}(6+2)-\Delta)$ had no effect (Figure 3C). FISH between Shh and SBE2 confirmed that the chromatin unfolding was confined to the $S h$-SBE6 region - even when the activator was recruited to SBE2 (Figure S3B and Table S3).

To test whether the differential effect of single vs double Tal-Vp64 targeting was due simply to the local concentration of 'activator' that could be recruited, we targeted Vp128 (8 copies of Vp16) to the Shh promoter and to SBE6 and SBE2 individually (Figure 3A). All three led to activation of Shh expression in ESCs (Figure 3D), but chromatin unfolding was only observed when Vp128 was recruited to the enhancers and not to the Shh promoter. In contrast to the recruitment of Vp64, Vp128 recruitment to either SBE6 or SBE2 alone was sufficient to induce this change in chromosome conformation (Figure 3E). Therefore, the amount of activator recruited to the Shh regulatory region seems crucial to the induction of visible levels of chromatin unfolding.

5C analysis in ESCs following Tale-Vp64 transfection did not reveal any direct interactions established between the Shh promoter and another sequence 5' of Shh when SBE6 and SBE2 are activated, either individually or together (Figures $3 \mathrm{~F}$ and $\mathrm{S} 3 \mathrm{C}$ ).

\section{Endogenous activators and co-activators also induce chromatin unfolding.}

Vp16 is a very effective transcriptional activator, but of viral origin. We therefore wished to analyse whether mammalian endogenous activators and co-activators could induce similar long-range chromatin changes across the genomic region 5' of Shh. The Mediator co-activator is known to be recruited to active enhancers and promoters (Allen and Taatjes, 2015; Yin et al., 2014) and can work alongside cohesin to alter 3D chromosome conformation upon enhancer driven gene activation (Kagey et al., 2010; Visel et al., 2009). Chromatin immunoprecipitation (ChIP) showed that Mediator is indeed recruited to the Shh promoter during the differentiation of 46c ESCs to NPCs (Figure 4A). 

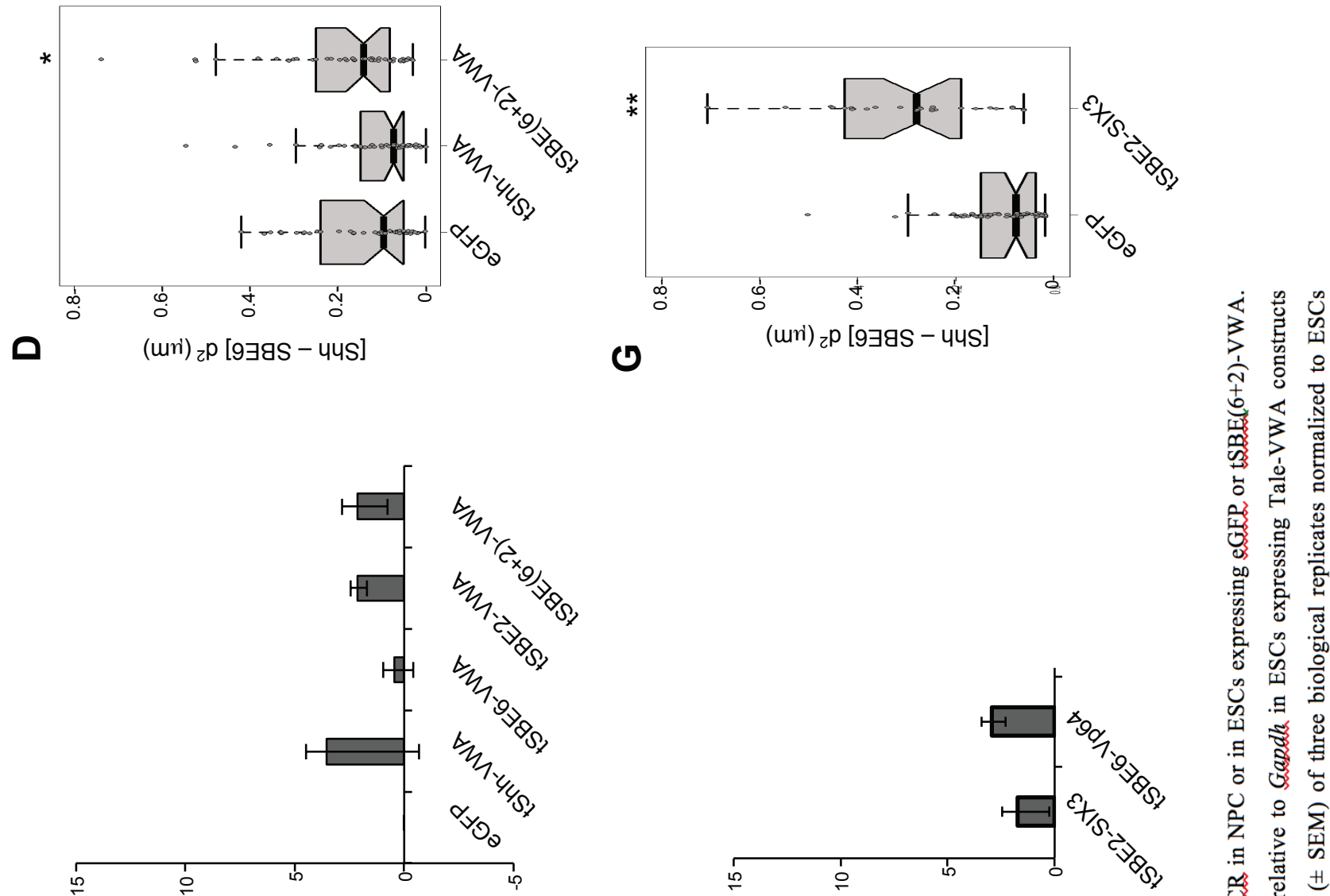

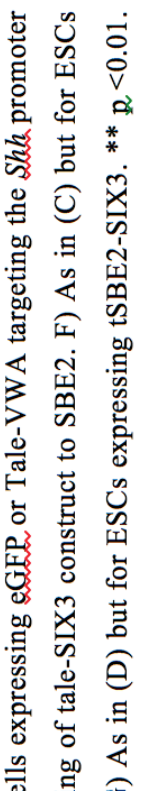

0
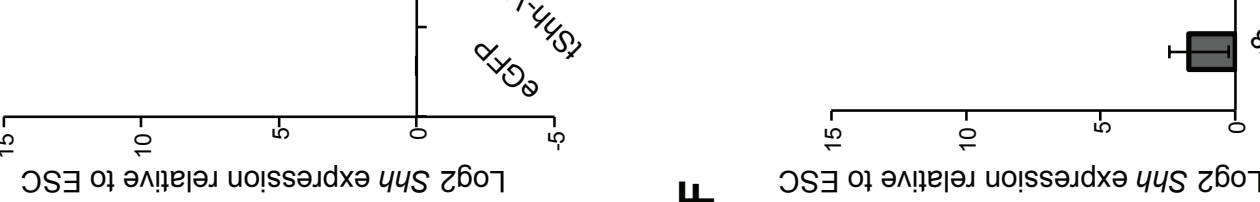

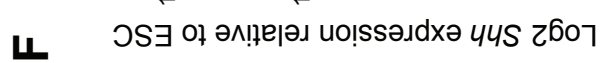
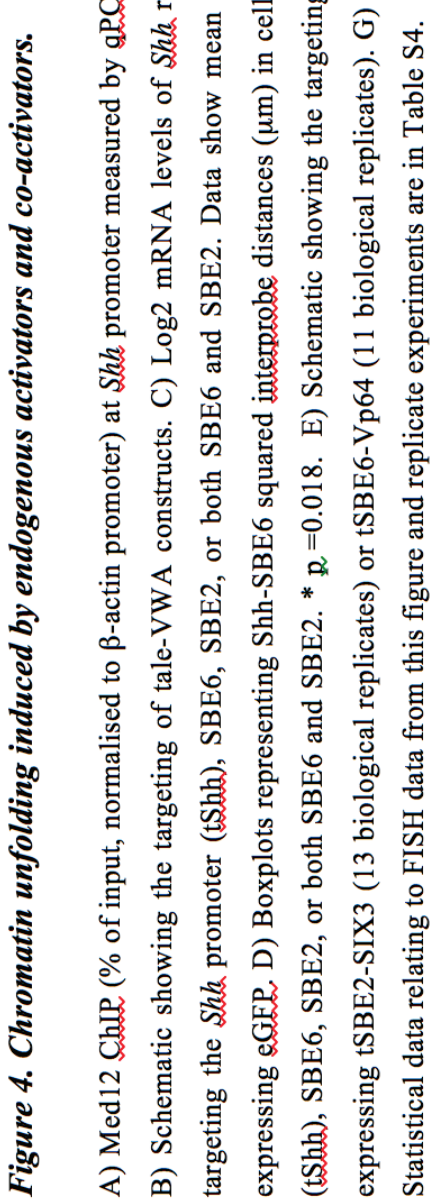
Mediator interacts with RNA polymerase II and many transcription factors, and is considered to bridge between them. Amongst the transcriptional activators that interact with Mediator is Vp16, which interacts with the Med25 subunit located in the tail domain of the complex (Milbradt et al., 2011; Vojnic et al., 2011). Med25 is recruited into the Mediator complex through its N-terminal Von Willebrand factor A (VWA) domain (Mittler et al., 2003). We therefore fused Tales to the Med25 VWA domain (Figure 4B). Compared to Tale-Vp16 fusions, Med25-VWA recruitment induced only very low levels of Shh expression, even for the Shh promoter targeted Tale (tShh-VWA) (Figure 4C). Nevertheless, when targeted to both SBE6 and SBE2, Tale-VWA promotes significant chromatin unfolding between SBE6 and Shh (Figure 4D and Table S4). Moreover, this also results in the recruitment of the Med 12 subunit of the Mediator kinase module at the Shh promoter, compatible with a long-range effect (Figure 4A).

For the most part, the endogenous TFs that bind to SBEs to activate Shh in neural tissues are unknown. However, Six homeobox 3 (SIX3) is known to bind to SBE2, and mutation of its binding site, or of SIX3 itself, affects Shh expression in the developing brain leading to severe holoprosencephaly (HPE) (Geng et al., 2008; Jeong et al., 2008). Six3 is also significantly upregulated during the ex vivo differentiation of ESCs to NPCs (Benabdallah et al., 2016). This prompted us to investigate whether SIX3 binding was sufficient to recapitulate chromatin unfolding in the region 5, of Shh. Tale-directed recruitment of SIX3 to SBE2 in ESCs (Figure 4E) induced only very low level and variable $S h$ expression (Figure 4F), but led to dramatic chromatin unfolding (Figure 4G, Table S4). Therefore recruitment of either an endogenous activator (SIX3) or co-activator (Mediator) to the gene desert 5' of Shh is capable of inducing an unfolding of long-range chromatin structure and this is not simply dependent on the induction of very high levels of Shh expression.

\section{Blocking of chromatin unfolding suggests a spreading-like mechanism.}

Chromatin unfolding (increased nuclear distances between SBE6/2 and Shh), and the absence of detectable enhancer-promoter looping/spatial juxtaposition, is suggestive of a more linear spreading/linking or tracking-like mechanism operating in the region 5' of Shh (Bulger and Groudine, 1999; Engel et al., 2008; Vernimmen and Bickmore, 2015). To test this model, we attempted to insert obstacles between SBE6 and Shh which might block such a mechanism. To do this we chose a site $65 \mathrm{~kb}$ upstream from the Shh TSS (chr5: 28859721; mm9) that lacked evidence of enhancer activity (H3K4me1/H3K27ac marks) during ESC-NPC differentiation (Benabdallh et al., 2016), and that does not show evolutionary conservation. We designed a Tale construct specific to this site (called NE for Non-Enhancer) and fused it to CTCF (tNE-CTCF) (Figure 5A). CTCF has been proposed to block an enhancer-promoter tracking mechanism at the H19/Igf2 locus (Engel et al., 2008) and to have general enhancer blocking functions (Burgess-Beusse et al., 2002). The introduction of tNE-CTCF, in 

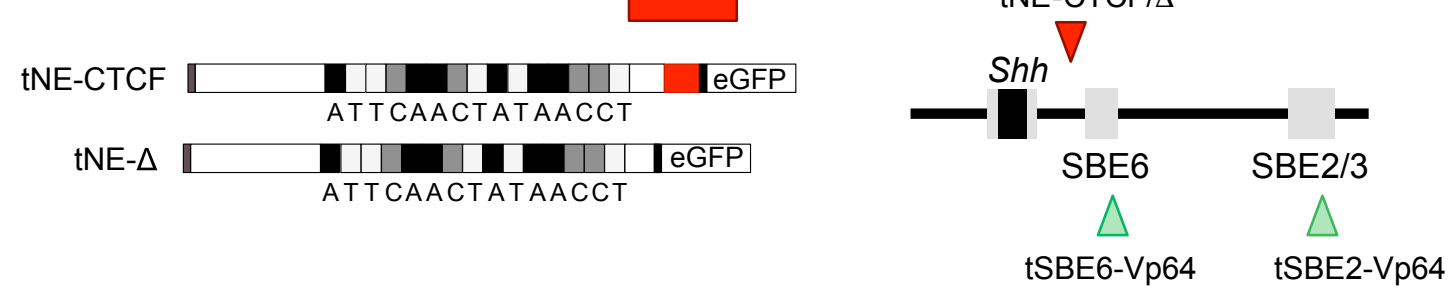

B
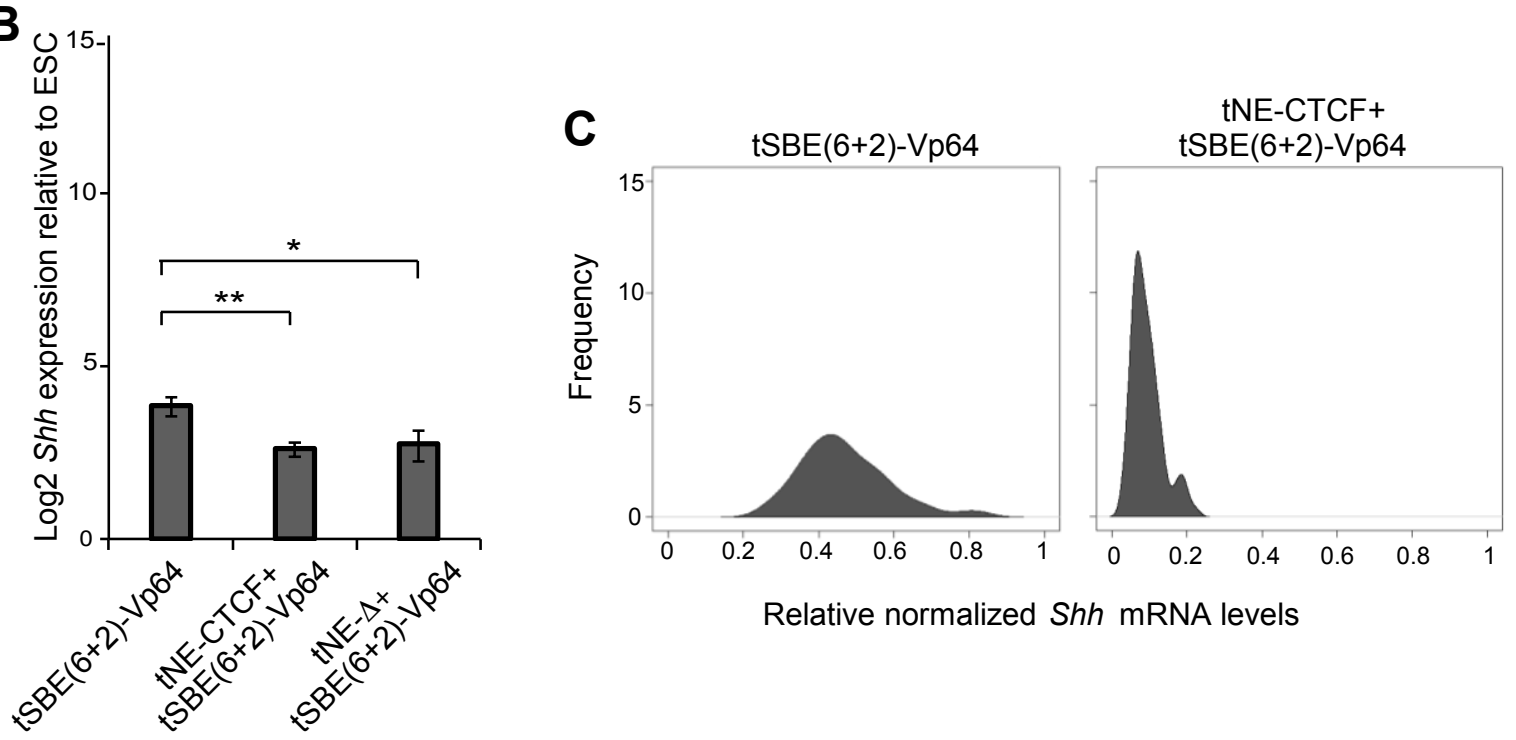

Relative normalized Shh mRNA levels
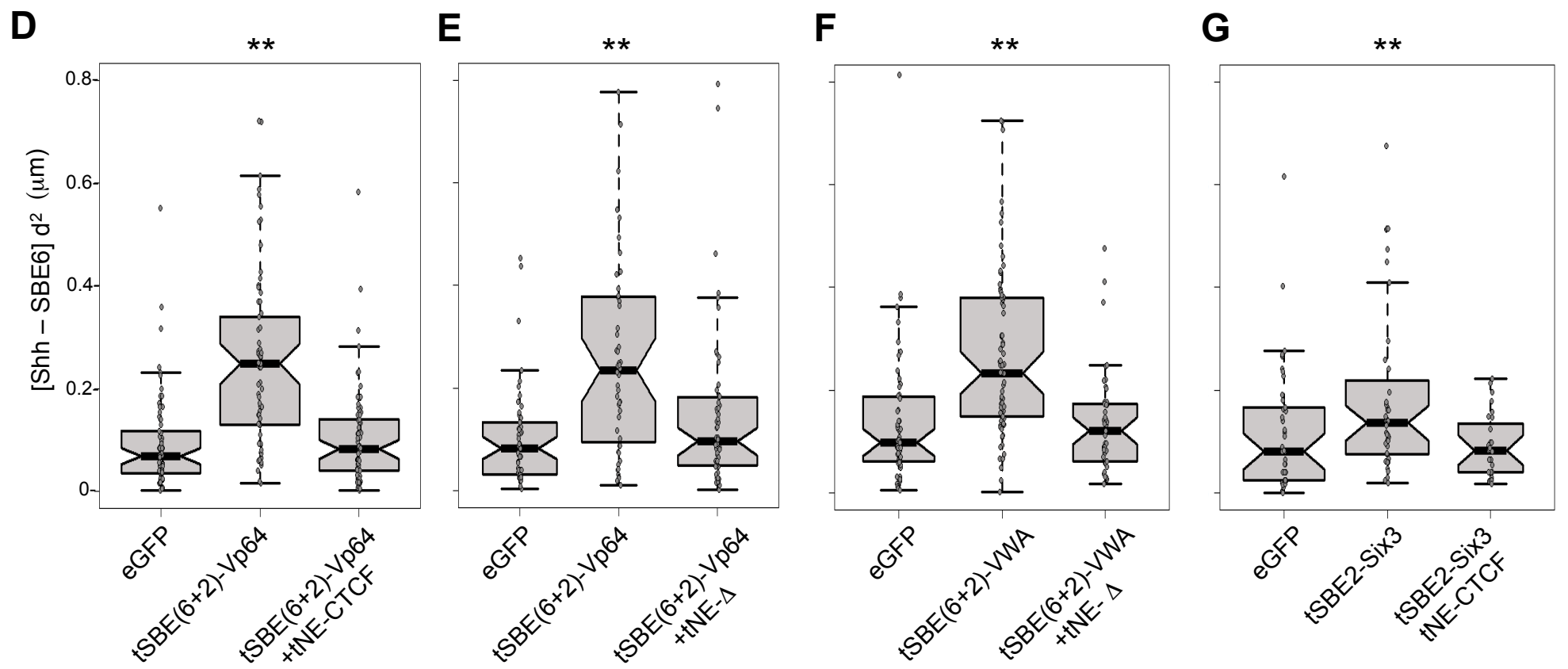

Figure 5. Chromatin unfolding is blocked by an intervening chromatin-bound proteins

A) Schematic showing Tales targeting the NE site with either no fusion protein (tNE- $\Delta$ ) or fused to CTCF (tNE-CTCF). B) Log2 mean ( \pm SEM) Shh mRNA levels relative to Gapdh in ESCs expressing Tale-VP64 fusions targeting SBE6 and SBE2 and in cells that also express either tNE-CTCF (3 biological replicates) or tNE- $\Delta$ (4 biological replicates). Data are normalized to those from ESCs expressing control eGEP Asterisks represent p-values for one-tailed Student t-test between conditions. ${ }^{*} \mathrm{p}<0.05$ and ${ }^{* *} \mathrm{p}<0.01$. C) Kernel density plots showing Shh expression in single ESCs expressing Tale-VP64 fusions targeting SBE6 + SBE2, and in these cells when tNE-CTCF is also expressed. Expression is normalised to that in ESCs. D and E) Boxplots showing ShhSBE6 squared interprobe distances $(\mu \mathrm{m})$ in ESCs expressing eGEP, Tale-VP64 fusions targeting SBE6 + SBE2, and these cells when either tNE-CTCF (D) or tNE- $\Delta$ (E) is also expressed. ${ }^{* *} \mathrm{p}<0.01$. F) As in E but using a Tale-VWA fusion targeting SBE6 and SBE2. G) As in (D) but using tSBE2-SIX3 to activate Shh. Statistical data for FISH data from this figure are in Table S5. 
bioRxiv preprint doi: https://doi.org/10.1101/155325; this version posted June 25, 2017. The copyright holder for this preprint (which was not certified by peer review) is the author/funder, who has granted bioRxiv a license to display the preprint in perpetuity. It is made available under aCC-BY-NC-ND 4.0 International license.

conjunction with Tale-Vp64 co-activation of SBE6 and SBE2 reduced Shh activation (Figure 5B). Single cell qRT-PCR confirmed that the majority of the cells transfected with tNE-CTCF+tSBE(6+2)Vp64 had very low levels of Shh expression (Figure 5C). The binding of tNE-CTCF prevented ShhSBE6 chromatin unfolding induced by the Tale-Vp64 co-activation of SBE6 and SBE2 (Figure 5D and Table S5) consistent with the intervening CTCF molecule interrupting a spreading mechanism initiated at SBE6/2. However, we found that the binding at NE of a Tale without any fused protein (tNE- $\Delta$ ) had the same negative impact on Shh expression (Figure 5B) and Shh-SBE6 chromatin unfolding (Figure 5E) as tNE-CTCF. Chromatin unfolding induced by Tale-mediated recruitment of Med25-VWA or SIX3 to SBE6/2 could be similarly blocked by co-transfection with tNE-CTCF or tNE- $\Delta$ (Figures $5 \mathrm{~F}$ and $5 \mathrm{G}$ ). These data suggest that induced Shh-SBE6 chromatin unfolding occurred through a mechanism that is impeded by a protein bound strongly at an intervening site, and that this negatively impacts on $S h h$ activation from a distance.

\section{Chromatin unfolding in the Shh regulatory domain involves poly(ADP-ribosyl)ation.}

Our data suggest that chromatin unfolding spreads within the region 5' of Shh. Histone acetylation can lead to cytological levels of chromatin decompaction (Toth et al., 2004; Lleres et al., 2009) and there are examples of histone acetylation spreading between an enhancer and target gene, and that is blocked by CTCF (Zhao and Dean, 2004). Shh activation using Tale-Vp64 constructs targeted to SBE6 or SBE2 did indeed induce histone acetylation (H3K27ac) but this was limited precisely to the Tale binding site - with no indication of spreading (Figure S4).

Another post-translational chromatin modification that can induce large-scale chromatin unfolding in vitro and in vivo is poly(ADP-ribosyl)ation (PARylation) catalysed by poly(ADP-ribose) polymerases, including PARP1 (Huletsky et al., 1989). Moreover, PARP1 and high levels of poly(ADP-ribose) have been linked with chromatin decompaction and gene activation at ecdysone and heat-shock induced puffs on Drosophila polytene chromosomes (Tulin and Spradling, 2003; Sawatsubashi et al., 2004). We therefore investigated whether PARP1 recruitment could induce chromatin unfolding at the Shh region, by targeting PARP1 to Shh, SBE6 or SBE2 using Tales (Figure 6A). PARP1 recruitment had a minimal affect on Shh expression (Figure 6B), but led to chromatin unfolding between Shh and SBE6 when targeted to SBE6 or SBE2 (Figure 6C and Table S6). Recruitment of PARP1 to the Shh promoter had no detectable affect on chromatin unfolding in the region. Moreover, PARP1 mediated chromatin unfolding, that had been initiated from either SBE6 or SBE2, could be blocked by co-transfection with tNE-CTCF (Figure 6C).

To assess if the chromatin unfolding seen by targeted recruitment of other activators - such as SIX3 (Fig 5C) - also involves PARP1 catalytic activity, we used the PARP inhibitor olaparib (Shen et 
A

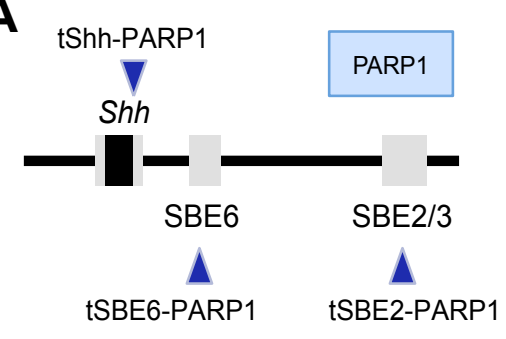

B

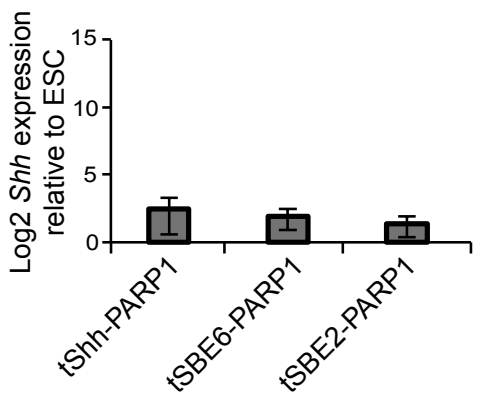

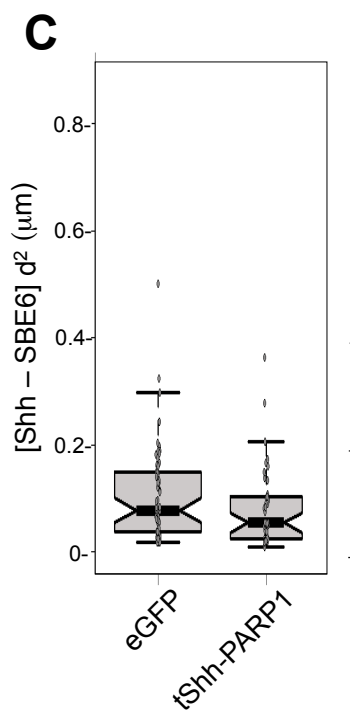

$\mathbf{F}$

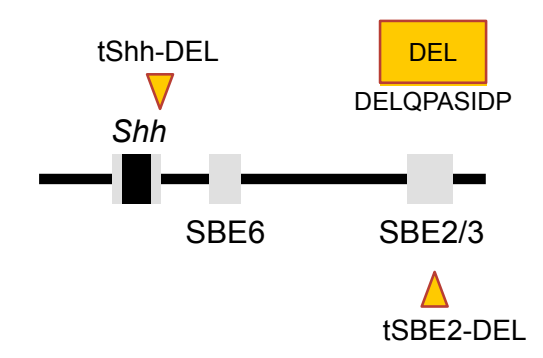

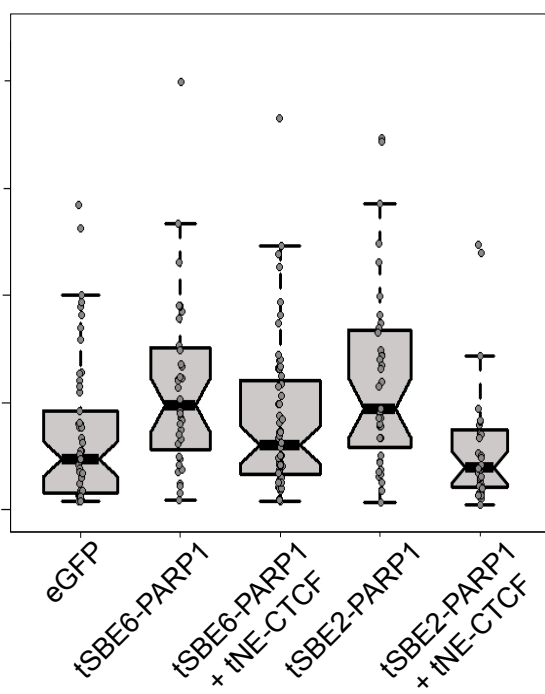

D

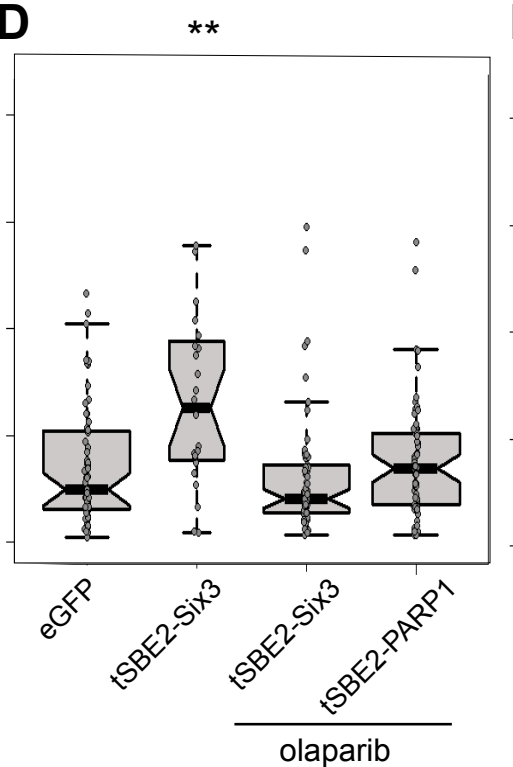

E $\quad * *$

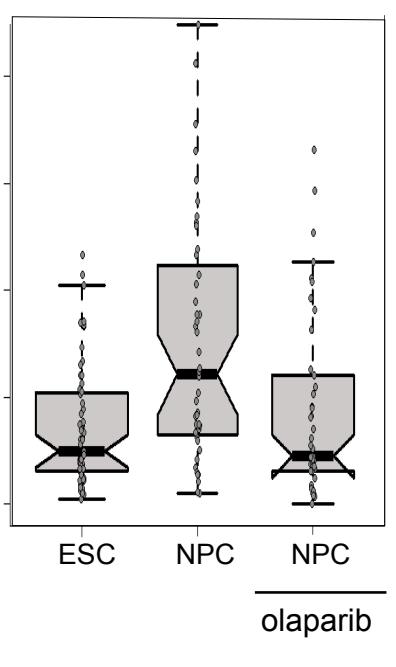

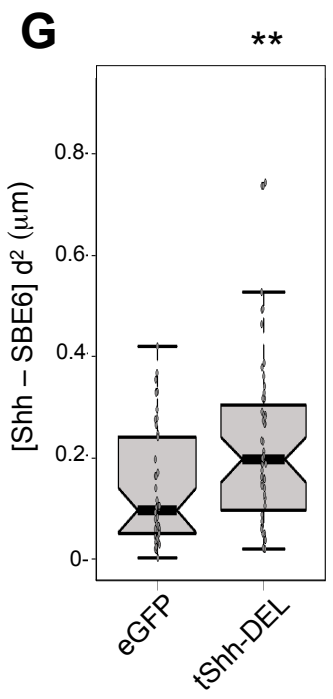

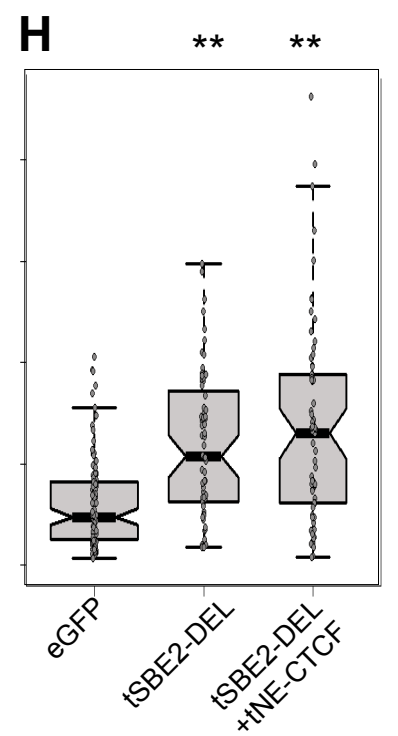

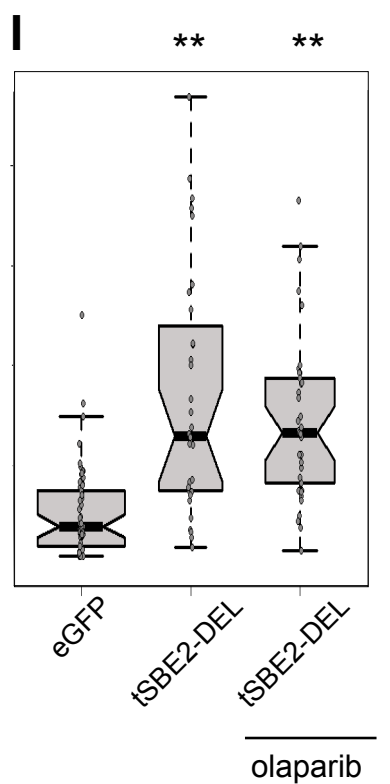

Figure 6. PARP1 catalytic activity induces chromatin unfolding.

A) Schematic of Tales that target PARP1 to the Shh promoter (tShb), SBE6 or SBE2. B) Log2 mRNA levels of Shh relative to Gapdh in ESCs expressing Tale-PARP1 constructs targeting the Shh promoter (tShb), SBE6, or SBE2. Data show mean ( \pm SEM) of 5 biological replicates normalized to ESCs expressing eGEP C) Boxplots showing Shh-SBE6 squared interprobe distances ( $\mu \mathrm{m}$ ) in ESCs expressing; (left) eGFP, or tShh-PARP1, (right) eGEP, tSBE6PARP1, tSBE6-PARP1 + tNE-CTCF, tSBE2-PARP1, tSBE2-PARP1 + tNE-CTCF. ${ }^{* *}{ }^{*}<0.01$. D) As in C but for ESCs expressing eGEP, tSBE2-Six3, and then in tSBE2-Six3 or tSBE2-PARP1 expressing cells treated with olaparib. E) Boxplots showing Shh-SBE6 squared interprobe distances ( $\mu \mathrm{m})$ in ESCs or NPCs, and in NPCs treated with elaparib. F) Schematic of Tales that target the DEL peptide to the Shh promoter or to SBE2. G-I) Boxplots showing ShhSBE6 squared interprobe distances $(\mu \mathrm{m})$ in ESCs expressing (G) eGFP or tShh-DEL, (H) tSBE2-DEL or tSBE2-DEL + tNE-CTCF, (I) tSBE2-DEL with and without olaparib treatment. Asterisks on FISH data represent Mann-Whitney U test significance between Tale-BP and eGEP transfected or ESC populations, 
al., 2015). Olaparib treatment prevented chromatin unfolding mediated by either SIX3 or PARP1 recruitment to SBE2 (tSBE2-SIX3 or tSBE2-PARP1) (Figure 6D). Olaparib also prevented the ShhSBE6 distance increases seen upon the differentiation of ESCs to NPCs (Figure 6E and Table S6).

We have previously shown that large-scale chromatin unfolding can be induced by Talemediated recruitment of a small acidic peptide DELQPASIDP (DEL) which has been shown to decompact chromatin without leading to gene activation (Carpenter et al., 2005; Therizols et al., 2014). Targeting DEL to the Shh region (Figure 6F) also led to visible chromatin decompaction (Figure 6G and H), but unlike our experiments tethering Vp16, Mediator, or PARP1, this was also seen when the DEL peptide was recruited directly to the $S h h$ promoter (Figure 6G). This result is similar to our previous studies in which the DEL peptide was recruited to the promoters of silent genes in ESCs (Therizols et al., 2014). Also unlike the chromatin decompaction induced by PARP1, transcriptional activators and co-activators, chromatin unfolding induced by the DEL peptide recruited to SBE2 was not blocked by tethering of an intervening CTCF (Figure 6H and Table S6), and it was not inhibited by olaparib (Figure 6I). These data suggest that chromatin decompaction induced in the regulatory region 5' of Shh, either during NPC differentiation or during synthetic activation, is quite distinct in its mechanism and its mode of propagation from that induced by the DEL peptide.

To better understand the nature of the unfolded chromatin upstream of $S h h$, we performed 2D-FISH with a fosmid probe for $S h h$, and a BAC probe that spans the $171 \mathrm{~kb}$ region from $50 \mathrm{~kb} 5^{\prime}$ of Shh up until SBE4 (Figure 7A) - the limit of the chromatin unfolding detected during NPC differentiation (Figure 1B). BAC probe hybridisation signals were classified as either compact point, or extended/'puffed' signals. Relative to control ESCs, there was a significant increase in the proportion of puffed signals observed when either Vp16 or PARP1 was recruited to the Shh regulatory domain, and this was inhibited when PARP1 recruitment was conducted in the presence of olaparib (Figure 7A and Table S7). These data suggest that there is a decompaction of the entire chromatin region extending 200kb 5' of $S h h$ when either an activator (Vp16) or PARP1 is recruited to this region, that requires the catalytic activity of PARP1 and that resembles the puffs seen on Drosophila polytene chromosomes.

Two scenarios can be envisaged for how PARP1 activity and PARylation contribute to largescale chromatin remodelling. PARylation, e.g. of a chromatin substrate, could lead directly to chromatin decompaction. Alternatively, hydrolysis of the ADP-ribose chains by poly(ADP-ribose) glycohydrolase (PARG) could be being used to generate ATP in the nucleus to support the activity of ATP-dependent chromatin remodelling enzymes (Wright et al., 2016). To distinguish between these two mechanisms, we depleted PARG using siRNA mediated knocked-down (Figure 7B). Relative to ESCs, chromatin decompaction in the Shh-SBE6 region, induced by recruitment of Vp16, PARP1 or 
A
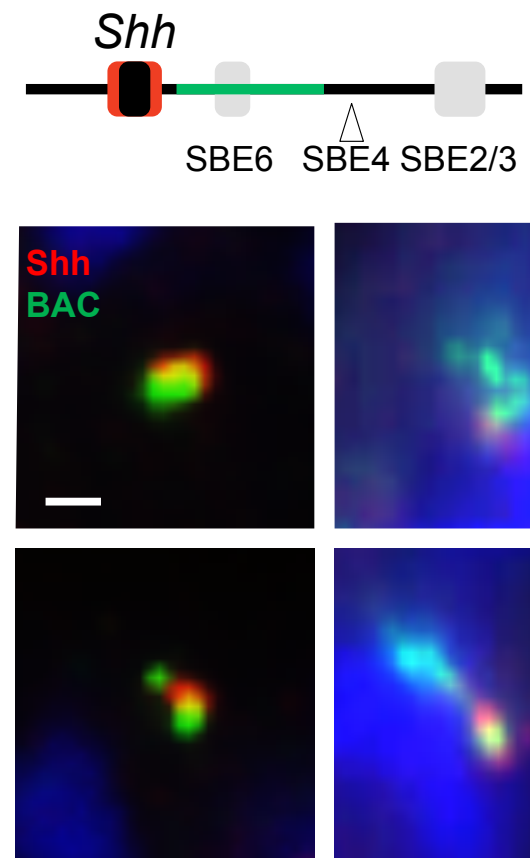

Point
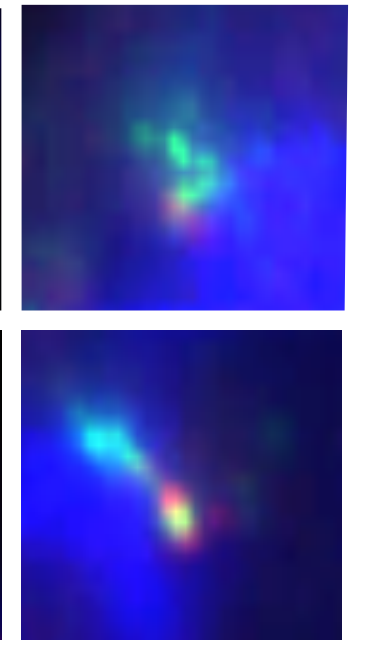

Extended

\section{$\square$ Extended BAC signal $\square$ Point BAC signal}

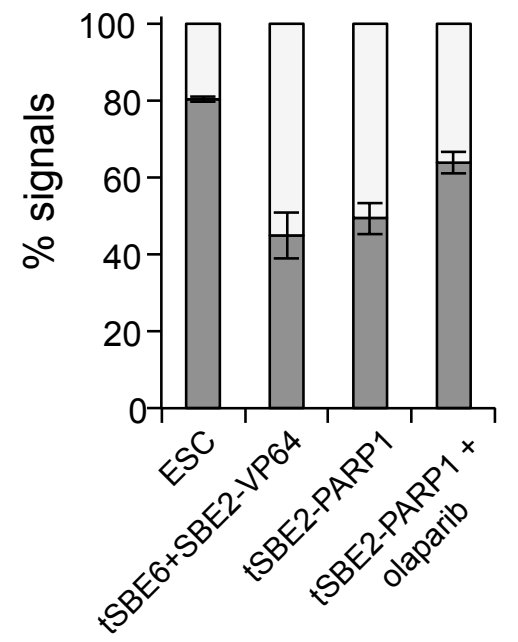

B

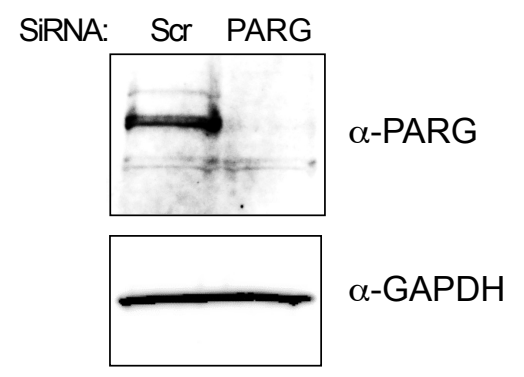

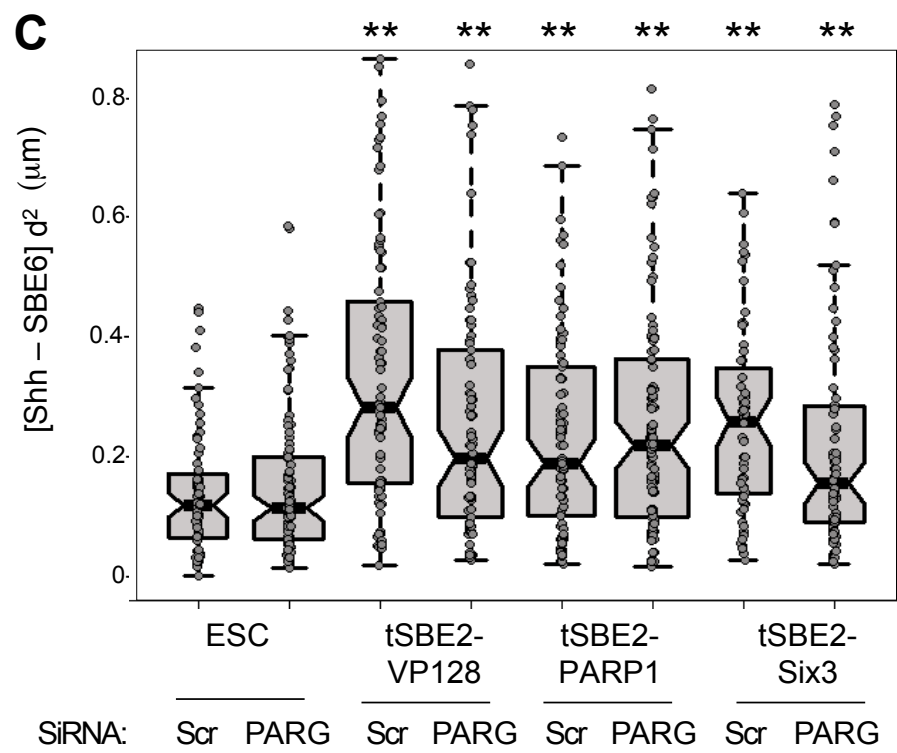

Figure 7. Chromosome puffing induced by activators and PARP1.

A) FISH with probes for Shh (red) and a BAC probe (RP24-323C22) spanning a 171kb region 5' of Shh (green). Examples of FISH signals with BAC signal classified as either "single point" (left) or extended (right) are shown. The bar chart shows the proportion of 'single' vs 'extended' BAC signals for ESC, tSBE(6+2)-Vp64, tSBE2-PARP1 and tSBE2-PARP1 treated with elaparib. Data are the average ( \pm SEM) of three technical replicates. Statistical significances from Fishers exact test and total signal counts are displayed in Table S7. B) Immunoblot with antibodies detecting PARG (top) or GAPDH control (bottom) in whole cell extracts from ESCs transfected with scrambled control siRNAs or SiRNAs targeting Parg. D) Boxplots representing Shh-SBE6 squared interprobe distances in ESCs, and in ESCs transfected with tSBE2-Vp128, tSBE2-SIX3, and tSBE2-PARP1 in cells transfected with scrambled (scr) or Parg siRNAs. Asterisks represent Mann-Whitney U test significance between Tales and scramble siRNA transfected ESC, * for p-values $<0.05$, ** for pvalues $<0.01$. Statistical data relating to FISH data are shown in Table S8. 
SIX3, was still detected after PARG knockdown (Figure 7C and Table S8). We conclude that most of the chromatin decompaction that we have detected as a result of recruitment of activators or PARP1 to the regulatory region 5' of Shh relies on PARP1 but not on PARG activity and so is like due to the process of PARylation itself. 


\section{Discussion}

A popular model of enhancer-promoter communication involves chromatin looping to juxtapose the two elements in 3D nuclear space (Vernimmen and Bickmore, 2015), and indeed we have provided visual evidence that supports this model in the context of long-range gene activation of Shh by the ZRS enhancer during limb development (Williamson et al., 2016). Recent results using live-cell imaging in Drosophila melanogaster to study nascent transcription driven by enhancer elements have challenged the idea of stable enhancer-promoter loops as the basis for enhancer-promoter communication (Fukaya et al., 2016). However, only a handful of enhancer-promoter interactions have been studied in detail and validated, and therefore the generality of a chromatin looping mechanism remains unclear. Here we have analysed the spatial relationship between Shh and its neural enhancers SBE6, SBE4 and SBE2/SBE3 using FISH and 5C during neural differentiation and, surprisingly, we identified a visible decompaction of the chromatin in the $350 \mathrm{~kb}$ region between $S h h$ and SBE4, with no evidence for chromatin loops being formed between Shh and enhancers in this region. Chromatin unfolding is dependent on a regulatory element (SBE6), that we have previously shown becomes activated during NPC differentiation, and that in vivo has activity in the floor plate region of the neural tube - an important site of Shh expression (Benabdallah et al., 2016). Consistent with these data, chromatin decompaction between Shh and SBE6 is detected in the floor plate, but not in the dorsal neural tube in mouse embryos.

To dissect the mechanism leading to this chromatin decompaction, we used synthetic activators (based upon Tale-mediated recruitment of Vp16) to either induce $S h h$ expression directly through activator recruitment to the gene promoter, or to induce expression from a distance through recruitment to distal sites up to $400 \mathrm{~kb}$ away in the $S h h$ regulatory domain. Activation from a distance recapitulated the chromatin decompaction seen during NPC differentiation and this was not seen if activators, or co-activators were recruited directly to the Shh promoter, allowing us to exclude that large-scale chromatin decompaction is simply a consequence of Shh expression. Induction of chromatin decompaction was recapitulated using distal recruitment of an endogenous activator (Six3) or co-activator (Mediator).

Chromatin decompaction seems most compatible with a tracking or linking mechanism of enhancer action (Bulger and Groudine, 2011). Indeed, we could block chromatin decompaction and abrogate $S h h$ activation from a distance if a Tal effector protein was bound between Shh and the distal site of activator/coactivator recruitment. This was not generic to all forms of visible chromatin decompaction - for example that induced by recruitment of the DEL peptide (Carpenter et al., 2005; Therizols et al., 2014). Together, our results reveal a strong link between a distinct form of chromatin unfolding and robust $S h$ activation from a distance. 
bioRxiv preprint doi: https://doi.org/10.1101/155325; this version posted June 25,2017 . The copyright holder for this preprint (which was not certified by peer review) is the author/funder, who has granted bioRxiv a license to display the preprint in perpetuity. It is made available under aCC-BY-NC-ND 4.0 International license.

\section{PARP-dependent chromatin puffing and enhancer activation}

Both gene activation from a distance, and chromatin unfolding at $S h h$, could be induced by PARP1 recruitment and blocked by a PARP inhibitor (olaparib). PARylation has been shown to induce massive decompaction of nucleosome arrays in vitro (Poirier et al., 1982; Huletsky et al., 1989) and in vivo (Tulin and Spradling, 2003; Petesch and Lis, 2008). Substrates for PARylation include the core histones, histone $\mathrm{H} 1$ and other proteins that can remodel and relax chromatin structure (Gottschalk et al., 2009; Petesch and Lis, 2008; Timinszky et al., 2009; Ji and Tulin, 2010; Sellou et al., 2016).

Though PARP1 is usually studied in the context of DNA damage sensing and repair, it has also been associated with the regulation of gene expression (Ogino et al., 2007) and with active chromatin and regions with regulatory potential as assayed by DNase I hypersensitivity (Nalabothula et al., 2015). More specifically, PARP and Parp1-dependent PARylation have been implicated in gene regulation from distal enhancer elements that are controlled by nuclear hormone receptors including; ecdysone inducible puffs in Drosophila (Sawatsubashi et al., 2004) and the action of the liganded progesterone receptor in mammalian breast cancer cells (Wright et al., 2012). The function of PARP1 and PARylation at regulatory elements might be directly to open chromatin structure to facilitate access of other factors involved in transcriptional activation. A second possibility is more linked to the role of PARP-1 in DNA repair. There is growing evidence that DNA strand-breaks are important in transcriptional activation. Topoisomerase IIb dependent double-strand break formation, and the subsequent recruitment of Parp-1 activity, is required for signal-induced transcriptional gene activation (Ju et al., 2006). Single-strand nicks generated by topoisomerase I might also be important (Puc et al., 2016). Recruitment of PARP-1 might be through DNA breaks per se, through interaction with transcription factors or co-activator complexes, or through altered DNA structures associated with the activation of transcription (Lonskaya et al., 2005). Finally, the importance of PARylation might be not simply be in decondensing higher-order chromatin structures, but instead the nucleicacid like PAR chains may seed a phase separation state through liquid de-mixing (Altemeyer et al., 2015) that then organizes an enhancer-centred nuclear compartment that can concentrate or exclude other proteins and orchestrate the multi-step reactions linked to robust transcriptional activation (Hnisz et al., 2017). Further experimentation will be required to investigate these possibilities. 


\section{Experimental Procedures}

\section{Cell Culture, differentiation and transfection}

46c mouse embryonic stem cells (mESCs), derived from E14tg2A, contain a GFP insertion into the Sox1 locus (Ying et al., 2003). mESCs were cultured in GMEM supplemented with $10 \%$ foetal bovine serum (FBS), 1000 units/ml LIF, nonessential amino acids, sodium pyruvate, 2- $\beta$ mercaptoethanol, L-glutamine and penicillin/streptomycin. ESCs were differentiated into NPCs with N2B27 medium (Pollard et al., 2006; Taylor et al., 2013). ESCs were transfected with Tale plasmids using Lipofectamine ${ }^{\circledR} 2000$ Reagent (Invitrogen cat. $\mathrm{N}^{\circ} 11668$ ) and FAC-sorted for GFP as previously described (Therizols et al., 2014). Briefly, $1 \times 10^{6}$ ESCs were transfected in a 6-well plate with $2.5 \mu \mathrm{g}$ of plasmid and $7 \mu \mathrm{l}$ of Lipofectamine. The culture medium was changed $6 \mathrm{~h}$ after transfection. Transfected cells were sorted based on eGFP expression by FACS $24 \mathrm{~h}$ after transfection and re-seeded on slides or 6-well-plates. Flow cytometric analysis was performed using the $488 \mathrm{~nm}$ laser of a BD FACSAriaII SORP (Becton Dickinson) with 525/50 nm bandpass filters. BD FACSDiva software (Becton Dickinson, Version 6.1.2) was used for instrument control and data analysis.

For PARP inhibition, olaparib was added to ESC or NPC media to a concentration of $10 \mu \mathrm{M}$ $24 \mathrm{~h}$ after transfection or $5 \mathrm{~h}$ after FACs. For NPCs, cells were treated for $1.5 \mathrm{~h}$ and media was changed and cell were fixed for FISH.

For siRNA knockdown, scramble (GE Dharmacon, ON-TARGETplus Non-targeting Pool D001810-10-05) or PARG (GE Dharmacon, SMARTpool: ON-TARGETplus Parg siRNA L-04409101-0005) siRNAs were used. $3 \times 10^{5}$ ESCs were transfected with 100 pmol siRNA and $5 \mu 1$ Lipofectamine in a 6 -well plate. Media was changed after $16 \mathrm{~h}$ and at $24 \mathrm{~h}$ cells were transfected with plasmids as required. Cells were recovered at $72 \mathrm{~h}$ for expression analysis, immunoblotting and FISH.

\section{D-FISH}

$1 \times 10^{6}$ ESCs or NPCs were seeded on slides for $5 \mathrm{~h}$. Cells were fixed in $4 \%$ paraformaldehyde (pFA) for 10 mins at room temperature (r.t.) and then permeabilized using $0.5 \%$ TritonX for 10 mins (Eskeland et al., 2010). Fosmid clones were prepared and labelled with green-dUTP (Abbott Molecular 02N32-050, 00884999002913) or red-dUTP (ChromaTide Alexa Fluor 594-5-dUTP C11400). Approximately $150 \mathrm{ng}$ of labelled fosmid probes were used per slide, together with $15 \mu \mathrm{g}$ of mouse Cot1 DNA (GIBCO BRL) and $10 \mu \mathrm{g}$ salmon sperm DNA. Probes were denatured at $70^{\circ} \mathrm{C}$ for 5 min, reannealed with CotI DNA for $15 \mathrm{~min}$ at $37^{\circ} \mathrm{C}$ and hybridized to the denatured slides overnight. DNA was denatured at $80^{\circ} \mathrm{C}$ for 20 mins. FISH probes are described in Table S9. 
For 2D FISH, cells were swollen in $0.5 \%$ trisodium citrate $/ 0.25 \% \mathrm{KCl}$ followed by fixation in methanol acetic acid (MAA - 3:1 vol/vol). Slides were incubated in $100 \mu \mathrm{g} / \mathrm{ml}$ RNase A in 2 x SCC for 1 hour, washed in $2 \times \mathrm{SCC}$ and dehydrated through an alcohol series. Slides were denatured in $70 \%$ formamide $/ 2 \times \mathrm{SCC}$ for $75 \mathrm{~s}$ at $70^{\circ} \mathrm{C}$. Between $80-120 \mathrm{ng}$ of biotin- and digoxigenin-labeled probes were used per slide, with 8-12 $\mu \mathrm{g}$ of mouse Cot1 DNA (Invitrogen) and 10 g salmon sperm DNA. Probes were denatured at $70^{\circ} \mathrm{C}$ for 5 mins, reannealed with Cot 1 DNA for 15 mins at $37^{\circ} \mathrm{C}$ and hybridized to the denatured slides overnight at $37^{\circ} \mathrm{C}$. Slides were washed $4 \times 3$ minutes in $2 \mathrm{X} \mathrm{SSC}$ at $45^{\circ} \mathrm{C}, 4 \times 3 \mathrm{mins}$ in $0.1 \mathrm{X} \mathrm{SSC}$ at $60^{\circ} \mathrm{C}$ and transferred to $4 \mathrm{X} \mathrm{SCC}, 0.1 \%$ Tween 20 . Slides were counterstained in $0.5 \mu \mathrm{g} / \mathrm{ml}$ DAPI.

\section{Image Capture and Analysis}

Super-resolution images from 3D FISH were acquired using structured illumination microscopy (SIM) following a published protocol (Gustafsson et al., 2008). Samples were prepared on high precision cover-glass (Zeiss, Germany). 3D-SIM images were acquired on a N-SIM (Nikon Instruments, UK) using a 100x Nikon Plan Apo TIRF objective (NA 1.49, oil immersion) and refractive index matched immersion oil (Nikon Instruments). Images were captured using an Andor DU-897X-5254 EMCCD camera using 405, 488, 561 and 640nm laser lines. Step size for $z$ stacks was set to $0.12 \mu \mathrm{m}$ as required by the manufacturer's software. For each focal plane, 15 images (5 phases, 3 angles) were captured with the NIS-Elements software. SIM image processing, reconstruction and analysis were carried out using the N-SIM module of the NIS-Element Advanced Research software. Images were reconstructed using NiS Elements software (Nikon Instruments) from a $z$-stack comprising of no less than $1 \mu \mathrm{m}$ of optical sections. In all SIM image reconstructions the Wiener and Apodization filter parameters were kept constant.

For analysis of 2D FISH, slides were imaged using a Hamamatsu Orca AG CCD camera (Hamamatsu Photonics (UK) Ltd, Welwyn Garden City, UK) and a Zeiss Axioplan II fluorescence microscope with Plan-neofluar objectives, a 100W Hg source (Carl Zeiss, Welwyn Garden City, UK) and Chroma \#83000 triple band pass filter set (Chroma Technology Corp., Rockingham, VT) with the excitation filters installed in a motorised filter wheel (Prior Scientific Instruments, Cambridge, UK).

Image analysis was carried out using the Quantitation module of Volocity (PerkinElmer). Reconstructed SIM data was directly uploaded and analyzed on Volocity. The statistical significance of differences in mean-squared interprobe distances was assessed using the nonparametric MannWhitney U test to examine the null hypothesis. Each data set consisted of 20 to 50 nuclei (40 to 100 loci). Biological replicates are shown under their p-values in Supplemental figures and tables. 
bioRxiv preprint doi: https://doi.org/10.1101/155325; this version posted June 25,2017 . The copyright holder for this preprint (which was not certified by peer review) is the author/funder, who has granted bioRxiv a license to display the preprint in perpetuity. It is made available under aCC-BY-NC-ND 4.0 International license.

\section{RNA extraction and Real Time quantitative Polymerase Chain Reaction (qRT-PCR)}

RNA was prepared using RNeasy mini kit (Qiagen) according to the manufacturer's protocol, including a DNaseI (Qiagen) treatment for 15 mins at r.t. cDNA was synthesized from $2 \mu \mathrm{g}$ purified RNA with Superscript II reverse transcriptase (Invitrogen) primed with random hexamers (Promega).

Real-time PCR was carried on the Roche LightCycler 480 Real-Time PCR System using a Lightcycler 480 Sybr Green detection kit (Roche). The real-time thermal cycler was programmed as follows: 15 min Hotstart; 44 PCR cycles $\left(95^{\circ} \mathrm{C}\right.$ for $15 \mathrm{~s}, 55^{\circ} \mathrm{C}$ for $30 \mathrm{~s}, 72^{\circ} \mathrm{C}$ for $\left.30 \mathrm{~s}\right)$. For transcript analysis, a standard curve for each primer set was obtained using a mix of each of the cDNAs. The relative expression of each sample was measured by the Lightcycler software and normalized to the mean for Gapdh from replicates. Finally, the $\log 2$ of the ratio relative to eGFP transfected ESCs was calculated when mentioned. Primers for qRT-PCR are listed in Table S10. Ptn and Nrp1 expression primers were taken from (Therizols et al., 2014).

\section{Single Cell RT-qPCR}

RNA reverse transcription and cDNA pre-amplification from single cells were performed as previously described (Dalerba et al., 2011) with some modifications. Each well of a 96-well PCR plate was loaded with $5 \mu 12 \mathrm{x}$ Reaction Mix, $0.2 \mu 1$ Superscript III RT/Platinum Taq Mix with RNaseOUT Ribonuclease Inhibitor (Invitrogen Cells Direct One-Step qRT-PCR kit, Life Technologies), $2.5 \mu 1$ primer mix (containing $200 \mathrm{nM}$ of each gene-specific primer), $1.3 \mu 1 \mathrm{H}_{2} \mathrm{O}$. Single-cell suspensions from NPC differentiation or transfection were sorted on their GFP reporter into separate wells of the 96-well PCR plate. 32 cells were sorted into one well, to be used for serial dilution for generation of qRT-PCR standard curves. RNA reverse transcription and 22 cycles of cDNA pre-amplification were performed as previously described (Dalerba et al., 2011). The cDNA was diluted 1:5 in $\mathrm{H}_{2} \mathrm{O}$ and qRT-PCR performed as above using $9 \mu \mathrm{l}$ of this diluted cDNA.

\section{TALE Design \& Assembly}

Tales were designed using TAL Effector Nucleotide Targeter 2.0 software (Doyle et al., 2012) and the assembly was performed following the protocol described in (Therizols et al., 2014). Briefly, TALE DNA binding domains specific to the Shh promoter, SBE6, SBE2, and NE were assembled following the methods described in (Ding et al., 2013). DNA binding domains specific for 16 nucleotide sequences were generated by the modular assembly of 4 pre-assembled multimeric TALE repeat modules (three 4-mer and one 3-mer) into a modified TALEN backbone in which the BamHI-BsrGI 
fragment containing hFokI2-2A-eGFP was replaced by a gBlocks ${ }^{\circledR}$ (IDT) fragment encoding Vp642A-eGFP (Therizols et al., 2014). The BamHI-BglII fragment containing Vp64 of the Tale-Vp64 plasmid was deleted to generate Tale- $\Delta$.

To generate other Tal-fusions, the BamHI-NheI cloning site was further used to fuse the Tale with; the SA domain of LDB1 from gBlocks ${ }^{\circledR}$ (IDT), with CTCF, Six3 or PARP1 from GeneArt ${ }^{\circledR}$ (Life Technologies). To generate Tale-BP, the BamHI-NheI fragment containing Vp64 was replaced by a double strand oligonucleotide encoding the DELQPASIDP peptide (Carpenter et al., 2005; Therizols et al., 2014) .

\section{Chromatin Immunoprecipitation and Microarray processing}

For cross-link ChIP, 0.5-1 $\times 10^{7}$ ESC were first cross-linked with EGS (Pearce, Thermo Scientific, product no. 21565) in PBS at a final concentration of $2 \mathrm{mM}$ for $60 \mathrm{~min}$ at r.t. Formaldehyde was then added at a final concentration of $1 \%$ methanol-free formaldehyde (Thermo Scientific Pierce PN28906) and incubated at r.t. for $10 \mathrm{~min}$ followed by $5 \mathrm{~min}$ incubation with $125 \mathrm{mM}$ glycine and then washed in PBS. All buffers were supplemented with the following additives just prior to use: 0.2 mM PMSF, 1 mM DTT, 1x Protease inhibitors (Calbiochem, 539134-1SET) and 1x phosphatase inhibitors (Roche, PhosSTOP, 04906837001). Purified DNA was isolated using a QIAquick PCR Purification Kit (Qiagen). Med12 ChIP was performed as previously described (Vernimmen et al., 2007) using Med12 antibody (Bethyl laboratories, A300-774A) and quantitative (q)PCR was performed on a LightCycler480 (Roche) using the same guideline as for qRT-PCR. ChIP qPCR primers are displayed in Table S10.

For examination of histone acetylation by native ChIP, nuclei were prepared and resuspended in NB-R as previously described (Gilbert et al., 2003). Nuclei corresponding to $0.5-1 \times 10^{7}$ ESCs were digested with 50-80 Boehringer units of MNase (Sigma) for $10 \mathrm{~min}$ at r.t. in the presence of $20 \mu \mathrm{g}$ RNase A to obtain a chromatin ladder enriched in tri-, tetra-, and some pentanucleosomes. The reaction was stopped by adding equal volume of Stop Buffer $(215 \mathrm{mM} \mathrm{NaCl}, 10 \mathrm{mM}$ TrisHCl pH 8 , $20 \mathrm{mM}$ EDTA, $5.5 \%$ Sucrose, $2 \%$ Triton X-100, $0.2 \mathrm{mM}$ PMSF $1 \mathrm{mM}$ DTT and complete protease inhibitor cocktail) and incubated on ice overnight. Between 50-150 $\mu$ g released chromatin were precleared with Protein G Sepharose (GE Healthcare) for $2 \mathrm{hr}$ and mixed with $10 \mu \mathrm{g}$ prebound H3K27ac antibody (Millipore 07-360) in the presence of $100 \mu \mathrm{g}$ BSA and incubated for $3 \mathrm{hr}$ at $4{ }^{\circ} \mathrm{C}$. Beads were then washed $3 x$ with Wash Buffer $(150 \mathrm{mM} \mathrm{NaCl}, 10 \mathrm{mM}$ TrisHCl $\mathrm{pH}$ 8, 2 mM EDTA, 1\% NP40, $1 \%$ Sodium deoxycholate, 0.2mM PMSF, $1 \mathrm{mM}$ DTT and protease inhibitor cocktail) and once in TE. Bound complexes were eluted with $0.1 \mathrm{M} \mathrm{NaHCO3,} 1 \%$ SDS at r.t. Immunoprecipitated and input DNA were purified with Proteinase K (Genaxxon) and Qiagen PCR purification kit. 
For Nimblegen Arrays (H3K27ac), 10ng of input (MNase digested) or ChIP DNA were amplified using the WGA2 whole genome amplification kit (Sigma). Amplified material was labelled with $\mathrm{Cy} 3$ or $\mathrm{Cy} 5$ by random priming according to the NimbleGen ChIP-chip protocol (Roche). Samples were hybridized for $20 \mathrm{~h}$ and washed according to manufacturer's protocol. A custom $3 \times 720 \mathrm{~K}$ mouse tiling array (NimbleGen, Roche) containing 179,493 unique probes from different genomic regions, with each probe represented by 4 replicates was used. Arrays were scanned on a NimbleGen MS 200 Microarray scanner (Roche) using 100\% laser power and $2 \mu \mathrm{m}$ resolution. Raw signal intensities were quantified from TIFF images using MS 200 Data Collection software.

ChIP microarray data were analysed in $\mathrm{R}$ using the bioconductor packages Beadarray and Limma according to the Epigenesys NimbleGen ChIP-on-chip protocol 43. Scale normalization was used within replicates, to control inter-array variability. Enrichment scores are defined as $\log 2$ ChIP/Input signal.

\section{C primer, 5C library design and preparation}

3C library preparation was performed as previously described (Williamson et al., 2014). 1 x $10^{7}$ ESCs or NPCs were fixed with $1 \%$ formaldehyde for $10 \mathrm{~min}$ at r.t. Cross-linking was stopped with $125 \mathrm{mM}$ glycine for $5 \mathrm{~min}$ at r.t. followed by $15 \mathrm{~min}$ on ice. Cells were centrifuged at $400 \mathrm{~g}$ for $10 \mathrm{~min}$ at $4{ }^{\circ} \mathrm{C}$, supernatants were removed, and cell pellets were flash-frozen on dry ice. Cell pellets were then treated as previously described (Dostie and Dekker, 2007; Ferraiuolo et al., 2010; Williamson et al. 2016).

Briefly, 1-2 x $10^{7}$ fixed cells were incubated for $15 \mathrm{~min}$ on ice in $200 \mu \mathrm{l}$ of lysis buffer (10 $\mathrm{mM}$ Tris at $\mathrm{pH} 8.0,10 \mathrm{mM} \mathrm{NaCl}, 0.2 \% \mathrm{NP} 40$, supplemented with fresh protease inhibitor cocktail). Cells were then disrupted on ice with a dounce homogenizer (pestle B; $2 \times 20$ strokes); cell suspensions were transferred to Eppendorf tubes and centrifuged at $2000 \mathrm{~g}$ for $5 \mathrm{~min}$. Supernatants were removed, the cell pellets were washed twice with $100 \mu \mathrm{l}$ of $1 \times$ CutSmart buffer (New England Biolabs), and the cell pellet was resuspended in $100 \mu \mathrm{l}$ of $1 \times$ CutSmart buffer and divided into two Eppendorf tubes. $1 \times$ CutSmart buffer $(337 \mu \mathrm{L})$ was added to each tube, and the mixture was incubated for $10 \mathrm{~min}$ at $65^{\circ} \mathrm{C}$ with $0.1 \%$ SDS. Forty-four microliters of $10 \%$ Triton X-100 were added before overnight digestion with $400 \mathrm{U}$ of HindIII. The restriction enzyme was then inactivated by adding 86 $\mu 110 \%$ SDS and incubation for $30 \mathrm{~min}$ at $65^{\circ} \mathrm{C}$. Samples were then individually diluted into $7.62 \mathrm{ml}$ of ligation mix $(750 \mu \mathrm{l} 10 \%$ Triton X-100, $750 \mu \mathrm{l} 10 \times$ ligation buffer, $80 \mu 110 \mathrm{mg} / \mathrm{ml}$ of BSA, $80 \mu \mathrm{l}$ $100 \mathrm{mM}$ ATP, 3000 cohesive end units of T4 DNA ligase) and incubated for $2 \mathrm{~h}$ at $16^{\circ} \mathrm{C}$.

$3 \mathrm{C}$ libraries were incubated overnight at $65^{\circ} \mathrm{C}$ with $50 \mu \mathrm{l}$ of Proteinase $\mathrm{K}(10 \mathrm{mg} / \mathrm{ml})$ and an additional $50 \mu \mathrm{l}$ of Proteinase $\mathrm{K}$ the following day for $2 \mathrm{~h}$. The DNA was purified by one phenol and 
one phenol-chloroform extraction and precipitated with $0.1 \mathrm{vol}(800 \mu \mathrm{l})$ of $3 \mathrm{M} \mathrm{NaOAc}(\mathrm{pH} 5.2)$ and $2.5 \mathrm{vol}$ of cold EtOH $(20 \mathrm{ml})$. After at least $1 \mathrm{~h}$ at $-80^{\circ} \mathrm{C}$, the DNA was centrifuged at $20,000 \mathrm{~g}$ for 25 $\min$ at $4{ }^{\circ} \mathrm{C}$, and the pellets were washed with cold $70 \% \mathrm{EtOH}$. DNA was resuspended in $400 \mu \mathrm{l}$ of TE $(\mathrm{pH}$ 8.0) and transferred to Eppendorf tubes for another phenol-chloroform extraction and precipitation with $40 \mu \mathrm{l}$ of $3 \mathrm{M} \mathrm{NaOAc}(\mathrm{pH} 5.2$ ) and $1.1 \mathrm{ml}$ of cold EtOH. DNA was recovered by centrifugation and washed eight times with cold 70\% EtOH. Pellets were then dissolved in $100 \mu \mathrm{l}$ of TE (pH 8.0) and incubated with $1 \mu \mathrm{l}$ of $10 \mathrm{mg} / \mathrm{ml}$ RNase A for $15 \mathrm{~min}$ at $37^{\circ} \mathrm{C}$.

5C primers covering the USP22 (mm9, chr11: 60,917,307-61,017,307) and Shh (mm9, chr5: 28317087-30005000) regions, library design, and preparation, were performed as described (Williamson et al. 2016). 5C libraries were prepared and amplified with the A-key and P1-key primers as described previously (Fraser et al., 2012). 3C libraries were first titrated by PCR for quality control (single band, absence of primer dimers, etc.) and to verify that contacts were amplified at frequencies similar to that usually obtained from comparable libraries (same DNA amount from the same species and karyotype) (Dostie and Dekker, 2007; Fraser et al., 2010). We used 1-11 $\mu \mathrm{g}$ of 3C library per 5C ligation reaction.

5C primer stocks $(20 \mu \mathrm{M})$ were diluted individually in water on ice and mixed to a final concentration of $0.002 \mu \mathrm{M}$. Mixed diluted primers $(1.7 \mu \mathrm{l})$ were combined with $1 \mu \mathrm{l}$ of annealing buffer (10× NEBuffer 4, New England Biolabs) on ice in reaction tubes. Salmon testis DNA (1.5 $\mu \mathrm{g})$ was added to each tube, followed by the $3 \mathrm{C}$ libraries and water to a final volume of $10 \mu \mathrm{l}$. Samples were denatured for $5 \mathrm{~min}$ at $95^{\circ} \mathrm{C}$ and annealed for $16 \mathrm{~h}$ at $48^{\circ} \mathrm{C}$. Ligation with $10 \mathrm{U}$ of Taq DNA ligase was performed for $1 \mathrm{~h}$ at $48^{\circ} \mathrm{C}$. One-tenth $(3 \mu \mathrm{l})$ of each ligation was then PCR-amplified individually with primers against the A-key and P1-key primer tails. We used 26 or 28 cycles based on dilution series showing linear PCR amplification within that cycle range. The products from two to four PCR reactions were pooled before purifying the DNA on MinElute columns (Qiagen).

5C libraries were quantified on agarose gels and diluted to $0.0534 \mathrm{ng} / \mu \mathrm{L}$ (for Xpress template kit version 2.0) or $12 \mathrm{pmol}$ (for Ion Proton). One microliter of diluted 5C library was used for sequencing with an Ion Proton sequencer. Samples were sequenced as recommended by the manufacturer (Life Technologies).

Analysis of the 5C sequencing data was performed as described earlier (Berlivet et al., 2013). The sequencing data were processed through a Torrent $5 \mathrm{C}$ data transformation pipeline on Galaxy (https://main.g2.bx.psu.edu). Data were normalized by dividing the number of reads of each $5 \mathrm{C}$ contact by the total number of reads from the corresponding sequence run. All scales shown correspond to this ratio multiplied by $10^{3}$. Sequencing technical and biological replicates reads are displayed in Table S11. 


\section{Immunoblotting}

3 wells of a 6-well plate containing ESCs transfected with scramble or PARG siRNA were recovered $72 \mathrm{~h}$ after transfection. Cells were trypsinized, washed and resuspended in $50 \mu 1$ RIPA buffer $(10 \mathrm{mM}$ Tris-Cl (pH 8.0) 1 mM EDTA. 1\% Triton X-100. 0.1\% sodium deoxycholate. 0.1\% SDS. $140 \mathrm{mM}$ $\mathrm{NaCl} .1 \mathrm{mM}$ PMSF) and left on ice for $30 \mathrm{~min}$. After a $10 \mathrm{~min}$ spin at full speed, supernatant was mixed with 1x LDS NuPage loading buffer and 1x reducing agent and boiled at $95^{\circ} \mathrm{C}$ for 5 minutes. $20 \mu 1$ sample were run in a NuPAGE Novex 3-8\% Tris-Acetate Protein Gel (Thermo Fisher Scientific) and transferred using an iBlot ${ }^{\circledR} 2$ transfer system. Membrane was blocked with 5\% Milk in PBS-T for $1 \mathrm{~h}$ at r.t. For PARG detection, the membrane was incubated for $4 \mathrm{~h}$ at r.t. with anti-PARG antibody (PARG M-13, Santa Cruz sc-21480). For the loading control, GAPDH ab9485 was used. 


\section{Authors contributions}

NSB conducted most of the experiments and data analysis, prepared the figures and wrote the manuscript. IW assisted with 5C experiments and manuscript editing, RI assisted with ChIP and microarray analysis and manuscript editing, SB assisted with tissue section FISH and 2D FISH, GG assisted the microarray data processing. PT assisted with Tale design and building. WAB conceived of the study, designed the study, coordinated the study and wrote the manuscript. All authors gave final approval for publication. The authors declare that they have no competing interests

\section{Acknowledgements}

We thank the staff of the IGMM FACS and imaging facilities for invaluable technical help.

\section{Funding}

This work was supported by a PhD studentship to N.S.B funded through a grant from the UK Medical Research Council to the Edinburgh Super Resolution Imaging Consortium (ESRIC). Work in the group of W.A.B is supported by an MRC University Unit grant U127527202.

\section{Accession numbers}

Data from this paper are available at NCBI GEO under the series: GSE89557.

GSE89388: 5C data.

GSE89512: ChIP data 
bioRxiv preprint doi: https://doi.org/10.1101/155325; this version posted June 25, 2017. The copyright holder for this preprint (which was not certified by peer review) is the author/funder, who has granted bioRxiv a license to display the preprint in perpetuity. It is made available under aCC-BY-NC-ND 4.0 International license.

\section{References}

Allen, B.L., and Taatjes, D.J. (2015). The Mediator complex: a central integrator of transcription. Nat. Rev. Mol. Cell Biol. 16, 155-166.

Altmeyer, M., Neelsen, K.J., Teloni, F., Pozdnyakova, I., Pellegrino, S., Grøfte, M., Rask, M.B., Streicher, W., Jungmichel, S., Nielsen, M.L. and Lukas, J. (2015). Liquid demixing of intrinsically disordered proteins is seeded by poly(ADP-ribose). Nat Commun. 6,8088.

Anderson, E and Hill, R.E. (2014). Long-range regulation of the sonic hedgehog gene. Curr. Opin. Genet. Develop. 27, 54-59.

Benabdallah, N.S., and Bickmore, W.A. (2015). Regulatory Domains and Their Mechanisms. Cold Spring Harb Symp Quant Biol 80, 45-51.

Benabdallah NS, Gautier P, Hekimoglu-Balkan B, Lettice LA, Bhatia S, Bickmore WA. (2016). SBE6: a novel long-range enhancer involved in driving sonic hedgehog expression in neural progenitor cells._Open Biol. 6, pii: 160197.

Berlivet, S., Paquette, D., Dumouchel, A., Langlais, D., Dostie, J., and Kmita, M. (2013). Clustering of tissue-specific sub-TADs accompanies the regulation of HoxA genes in developing limbs. PLoS Genet. 9, e1004018.

Bulger, M., and Groudine, M. (2011) Functional and mechanistic diversity of distal transcription enhancers. Cell, 144, 327-339.

Burgess-Beusse, B., Farrell, C., Gaszner, M., Litt, M., Mutskov, V., Recillas-Targa, F., Simpson, M., West, A., and Felsenfeld, G. (2002). The insulation of genes from external enhancers and silencing chromatin. Proc Natl Acad Sci U S A. 99 Suppl 4, 16433-16437.

Carpenter, A.E., Memedula, S., Plutz, M.J., and Belmont, A.S. (2005). Common effects of acidic activators on large-scale chromatin structure and transcription. Mol. Cell. Biol. 25, 958-968.

Carter, D., Chakalova, L., Osborne, C.S., Dai, Y., and Fraser, P. (2002). Long-range chromatin regulatory interactions in vivo. Nat. Genet. 32, 623-626.

Dalerba, P., Kalisky, T., Sahoo, D., Rajendran, P.S., Rothenberg, M.E., Leyrat, A.A., Sim, S., Okamoto, J., Johnston, D.M., Qian, D., et al. (2011). Single-cell dissection of transcriptional heterogeneity in human colon tumors. Nat. Biotechnol. 29, 1120-1127.

Deng, W., Lee, J., Wang, H., Miller, J., Reik, A., Gregory, P.D., Dean, A., and Blobel, G.A. (2012). Controlling long-range genomic interactions at a native locus by targeted tethering of a looping factor. Cell 149, 1233-1244.

Deng, W., Rupon, J.W., Krivega, I., Breda, L., Motta, I., Jahn, K.S., Reik, A., Gregory, P.D., Rivella, S., Dean, A., et al. (2014). Reactivation of developmentally silenced globin genes by forced chromatin looping. Cell 158, 849-860.

Ding, Q., Lee, Y.-K., Schaefer, E.A.K., Peters, D.T., Veres, A., Kim, K., Kuperwasser, N., Motola, D.L., Meissner, T.B., Hendriks, W.T., et al. (2013). A TALEN genome-editing system for generating human stem cell-based disease models. Cell Stem Cell 12, 238-251.

Dostie, J., and Dekker, J. (2007). Mapping networks of physical interactions between genomic elements using 5C technology. Nat. Protoc. 2, 988-1002.

Doyle, E.L., Booher, N.J., Standage, D.S., Voytas, D.F., Brendel, V.P., Vandyk, J.K., and Bogdanove, A.J. (2012). TAL Effector-Nucleotide Targeter (TALE-NT) 2.0: tools for TAL effector design and target prediction. Nucleic Acids Res. 40, W117-22.

Engel, N., Raval, A.K., Thorvaldsen, J.L., and Bartolomei, S.M. (2008). Three-dimensional 
bioRxiv preprint doi: https://doi.org/10.1101/155325; this version posted June 25, 2017. The copyright holder for this preprint (which was not certified by peer review) is the author/funder, who has granted bioRxiv a license to display the preprint in perpetuity. It is made available under aCC-BY-NC-ND 4.0 International license.

conformation at the H19/Igf2 locus supports a model of enhancer tracking. Hum. Mol. Genet. 17, 3021-3029.

van den Engh, G., Sachs, R., and Trask, B.J. (1992). Estimating genomic distance from DNA sequence location in cell nuclei by a random walk model. Science 257, 1410-1412.

Eskeland, R., Leeb, M., Grimes, G.R., Kress, C., Boyle, S., Sproul, D., Gilbert, N., Fan, Y., Skoultchi, A.I., Wutz, A., et al. (2010). Ring1B compacts chromatin structure and represses gene expression independent of histone ubiquitination. Mol. Cell 38, 452-464.

Fraser, J., Rousseau, M., Blanchette, M., and Dostie, J. (2010). Computing chromosome conformation. Methods Mol. Biol. 674, 251-268.

Fraser, J., Ethier, S.D., Miura, H., and Dostie, J. (2012). A Torrent of data: mapping chromatin organization using 5C and high-throughput sequencing. Methods Enzymol. 513, 113-141.

Fukaya, T., Lim, B., and Levine, M. (2016). Enhancer Control of Transcriptional Bursting. Cell. 166, 358-368.

Geng, X., Speirs, C., Lagutin, O., Inbal, A., Liu, W., Solnica-Krezel, L., Jeong, Y., Epstein, D.J., and Oliver, G. (2008). Haploinsufficiency of Six3 fails to activate Sonic hedgehog expression in the ventral forebrain and causes holoprosencephaly. Dev. Cell 15, 236-247.

Gilbert, N., Boyle, S., Sutherland, H., de Las Heras, J., Allan, J., Jenuwein, T., and Bickmore, W.A. (2003). Formation of facultative heterochromatin in the absence of HP1. EMBO J. 22, 5540-5550.

Gilbert N, Boyle S, Fiegler H, Woodfine K, Carter NP, Bickmore WA. (2004). Chromatin architecture of the human genome: gene-rich domains are enriched in open chromatin fibers. Cell 118 , $555-566$.

Gottschalk, A.J., Timinszky, G., Kong, S.E., Jin, J., Cai, Y., Swanson, S.K., Washburn, M.P., Florens, L., Ladurner, A.G., Conaway, J.W., et al. (2009). Poly(ADP-ribosyl)ation directs recruitment and activation of an ATP-dependent chromatin remodeler. Proc. Natl. Acad. Sci. U. S. A. 106, 1377013774.

Gustafsson, M.G.L., Shao, L., Carlton, P.M., Wang, C.J.R., Golubovskaya, I.N., Cande, W.Z., Agard, D.A., Sedat, J.W., Agard, D.A., Hiraoka, Y., et al. (2008). Three-dimensional resolution doubling in wide-field fluorescence microscopy by structured illumination. Biophys. J. 94, 4957-4970.

Hatzis, P., and Talianidis, I. (2002). Dynamics of enhancer-promoter communication during differentiation-induced gene activation. Mol. Cell 10, 1467-1477.

Hnisz D, Shrinivas K, Young RA, Chakraborty AK, Sharp PA. (2017) A Phase Separation Model for Transcriptional Control. Cell. 169, 13-23.

Huletsky, A., de Murcia, G., Muller, S., Hengartner, M., Ménard, L., Lamarre, D., and Poirier, G.G. (1989) The effect of poly(ADP-ribosyl)ation on native and H1-depleted chromatin. A role of poly(ADP-ribosyl)ation on core nucleosome structure. J. Biol. Chem. 264, 8878-8886.

Jeong, Y. (2006). A functional screen for sonic hedgehog regulatory elements across a $1 \mathrm{Mb}$ interval identifies long-range ventral forebrain enhancers. Development 133, 761-772.

Jeong, Y., Leskow, F.C., El-Jaick, K., Roessler, E., Muenke, M., Yocum, A., Dubourg, C., Li, X., Geng, X., Oliver, G., et al. (2008). Regulation of a remote Shh forebrain enhancer by the Six3 homeoprotein. Nat. Genet. 40, 1348-1353.

Ji, Y. and Tulin, A.V. (2010). The roles of PARP1 in gene control and cell differentiation. Curr. Opin. Genet. Dev. 20, 512-518.

Ju, B.G., Lunyak, V.V., Perissi, V., Garcia-Bassets, I., Rose, D.W., Glass, C.K. and Rosenfeld, M.G. (2016). A topoisomerase IIbeta-mediated dsDNA break required for regulated transcription. 
bioRxiv preprint doi: https://doi.org/10.1101/155325; this version posted June 25, 2017. The copyright holder for this preprint (which was not certified by peer review) is the author/funder, who has granted bioRxiv a license to display the preprint in perpetuity. It is made available under aCC-BY-NC-ND 4.0 International license.

Science. 312, 1798-1802.

Kagey, M.H., Newman, J.J., Bilodeau, S., Zhan, Y., Orlando, D.A., van Berkum, N.L., Ebmeier, C.C., Goossens, J., Rahl, P.B., Levine, S.S., et al. (2010). Mediator and cohesin connect gene expression and chromatin architecture. Nature 467, 430-435.

Kim TK, Hemberg M, Gray JM, Costa AM, Bear DM, Wu J, Harmin DA, Laptewicz M, BarbaraHaley K, Kuersten S, Markenscoff-Papadimitriou E, Kuhl D, Bito H, Worley PF, Kreiman G, Greenberg ME. (2010). Widespread transcription at neuronal activity-regulated enhancers. Nature 465,182-187.

Lleres, D., James, J., Swift, S., Norman, D.G., and Lamond, A.I. (2009). Quantitative analysis of chromatin compaction in living cells using FLIM-FRET. J. Cell Biol 187, 481-496.

Lonskaya, I., Potaman, V.N., Shlyakhtenko, L.S., Oussatcheva, E.A., Lyubchenko, Y.L., Soldatenkov, V.A. (2005). Regulation of poly(ADP-ribose) polymerase-1 by DNA structure-specific binding. J. Biol. Chem. 280, 17076-17083

Matsumoto, K., and Hirose, S. (2004). Visualization of unconstrained negative supercoils of DNA on polytene chromosomes of Drosophila. J. Cell Sci. 117, 3797-3805.

Mittler, G., Stühler, T., Santolin, L., Uhlmann, T., Kremmer, E., Lottspeich, F., Berti, L., Meisterernst, M. (2003). A novel docking site on Mediator is critical for activation by VP16 in mammalian cells. EMBO J. 22, 6494-6504.

Milbradt, A.G., Kulkami, M., Yi, T., Takeuchi, K., Sun, Z.Y., Luna, R.E., Selenko, P., Näär, A.M,. and Wagner G. (2011). Structure of the VP16 transactivator target in the Mediator. Nat. Struct .Mol. Biol. 18, 410-415.

Nalabothula, N., Al-jumaily, T., Eteleeb, A.M., Flight, R.M., Xiaorong, S., Moseley, H., Rouchka, E.C., and Fondufe-Mittendorf, Y.N. (2015). Genome-Wide Profiling of PARP1 Reveals an Interplay with Gene Regulatory Regions and DNA Methylation. PLoS One 10, e0135410.

Naughton, C., Avlonitis, N., Corless, S., Prendergast, J.G., Mati, I.K., Eijk, P.P., Cockroft, S.L., Bradley, M., Ylstra, B., and Gilbert, N. (2013). Transcription forms and remodels supercoiling domains unfolding large-scale chromatin structures. Nat. Struct. Mol. Biol. 20, 387-395.

Ogino, H., Nozaki, T., Gunji, A., Maeda, M., Suzuki, H., Ohta, T., Murakami, Y., Nakagama, H., Sugimura, T., and Masutani, M. (2007). Loss of Parp- 1 affects gene expression profile in a genomewide manner in ES cells and liver cells. BMC Genomics 8, 41 .

Petesch, S.J., and Lis, J.T. (2008). Rapid, transcription-independent loss of nucleosomes over a large chromatin domain at Hsp70 loci. Cell 134, 74-84.

Poirier, G.G., de Murcia, G., Jongstra-Bilen, J., Niedergang, C. and Mandel, P. (1982) Poly(ADPribosyl)ation of polynucleosomes causes relaxation of chromatin structure. Proc Natl Acad Sci U S A. $79,3423-3427$.

Pollard, S.M., Benchoua, A., and Lowell, S. (2006). Neural stem cells, neurons, and glia. Methods Enzymol. 418, 151-169.

Pradeepa, M.M., Grimes, G.R., Kumar, Y., Olley, G., Taylor, G.C.A., Schneider, R., and Bickmore, W.A. (2016). Histone H3 globular domain acetylation identifies a new class of enhancers. Nat. Genet. $48,681-686$.

Puc, J., Kozbial, P., Li, W., Tan, Y., Liu, Z., Suter, T., Ohgi, K.A., Zhang, J., Aggarwal, A.K. and Rosenfeld MG. (2015). Ligand-dependent enhancer activation regulated by topoisomerase-I activity. Cell. $160,367-80$

Sawatsubashi. S., Maki, A., Ito, S., Shirode, Y., Suzuki, E., Zhao, Y., Yamagata, K., Kouzmenko, A., 
bioRxiv preprint doi: https://doi.org/10.1101/155325; this version posted June 25, 2017. The copyright holder for this preprint (which was not certified by peer review) is the author/funder, who has granted bioRxiv a license to display the preprint in perpetuity. It is made available under aCC-BY-NC-ND 4.0 International license.

Takeyama, K. and Kato S. (2004). Ecdysone receptor-dependent gene regulation mediates histone poly(ADP-ribosyl)ation. Biochem Biophys Res Commun. 320, 268-272.

Sellou, H., Lebeaupin, T., Chapuis, C., Smith, R., Hegele, A., Singh, H.R., Kozlowski, M., Bultmann, S., Ladurner, A.G., Timinszky, G. and Huet, S. (2016). The poly(ADP-ribose)-dependent chromatin remodeler Alc1 induces local chromatin relaxation upon DNA damage. Mol. Biol. Cell. 27, 37913799.

Shen, Y., Aoyagi-Scharber, M., and Wang B. (2015) Trapping Poly(ADP-Ribose) Polymerase. J Pharmacol Exp Ther. 353, 446-457.

Shlyueva, D., Stampfel, G., and Stark, A. (2014). Transcriptional enhancers: from properties to genome-wide predictions. Nat. Rev. Genet. 15, 272-286.

Smallwood A, and Ren B. (2013). Genome organization and long-range regulation of gene expression by enhancers. Curr Opin Cell Biol. 25, 387-394.

Taylor, G.C.A., Eskeland, R., Hekimoglu-Balkan, B., Pradeepa, M.M., and Bickmore, W.A. (2013). H4K16 acetylation marks active genes and enhancers of embryonic stem cells, but does not alter chromatin compaction. Genome Res. 23, 2053-2065.

Therizols, P., Illingworth, R.S., Courilleau, C., Boyle, S., Wood, A.J., and Bickmore, W.A. (2014). Chromatin decondensation is sufficient to alter nuclear organization in embryonic stem cells. Science $346,1238-1242$.

Timinszky, G., Till, S., Hassa, P.O., Hothorn, M., Kustatscher, G., Nijmeijer, B., Colombelli, J., Altmeyer, M., Stelzer, E.H.K., Scheffzek, K., et al. (2009). A macrodomain-containing histone rearranges chromatin upon sensing PARP1 activation. Nat. Struct. Mol. Biol. 16, 923-929.

Tolhuis, B., Palstra, R.J., Splinter, E., Grosveld, F., and de Laat, W. (2002). Looping and interaction between hypersensitive sites in the active beta-globin locus. Mol. Cell 10, 1453-1465.

Toth, K.F., Knoch, T.A., Wachsmuth, M., Frank-Stohr, M., Stohr, M.,Bacher, C.P., Muller, G., Rippe, K. (2004). Trichostatin A-induced histone acetylation causes decondensation of interphase chromatin. J Cell Sci 117, 4277-4287.

Tulin, A., and Spradling, A. (2003). Chromatin loosening by poly(ADP)-ribose polymerase (PARP) at Drosophila puff loci. Science 299, 560-562.

Vernimmen, D., De Gobbi, M., Sloane-Stanley, J.A., Wood, W.G., and Higgs, D.R. (2007). Longrange chromosomal interactions regulate the timing of the transition between poised and active gene expression. EMBO J. 26, 2041-2051.

Vernimmen, D. and Bickmore, W.A. (2015). The Hierarchy of Transcriptional Activation: From Enhancer to Promoter. Trends Genet. 3, 696-708.

Visel, A., Blow, M.J., Li, Z., Zhang, T., Akiyama, J.A., Holt, A., Plajzer-Frick, I., Shoukry, M., Wright, C., Chen, F., et al. (2009). ChIP-seq accurately predicts tissue-specific activity of enhancers. Nature 457, 854-858.

Vojnic, E., Mourão, A., Seizl, M., Simon, B., Wenzeck, L., Larivière, L., Baumli, S., Baumgart, K., Meisterernst, M., Sattler, M., et al. (2011). Structure and VP16 binding of the Mediator Med25 activator interaction domain. Nat. Struct. Mol. Biol. 18, 404-409.

Wang, Q., Carroll, J.S., and Brown, M. (2005). Spatial and temporal recruitment of androgen receptor and its coactivators involves chromosomal looping and polymerase tracking. Mol. Cell 19, 631-642.

Williamson, I., Eskeland, R., Lettice, L.A., Hill, A.E., Boyle, S., Grimes, G.R., Hill, R.E., and Bickmore, W.A. (2012). Anterior-posterior differences in HoxD chromatin topology in limb development. Development 139, 3157-3167. 
bioRxiv preprint doi: https://doi.org/10.1101/155325; this version posted June 25, 2017. The copyright holder for this preprint (which was not certified by peer review) is the author/funder, who has granted bioRxiv a license to display the preprint in perpetuity. It is made available under aCC-BY-NC-ND 4.0 International license.

Williamson, I., Berlivet, S., Eskeland, R., Boyle, S., Illingworth, R.S., Paquette, D., Dostie, J., and Bickmore, W.A. (2014). Spatial genome organization: contrasting views from chromosome conformation capture and fluorescence in situ hybridization. Genes Dev. 28, 2778-2791.

Williamson, I., Lettice, L.A., Hill, R.E., and Bickmore, W.A. (2016). Shh and ZRS enhancer colocalisation is specific to the zone of polarizing activity. Development. 143, 2994-3001.

Wright RH, Castellano G, Bonet J, Le Dily F, Font-Mateu J, Ballaré C, Nacht AS, Soronellas D, Oliva B, Beato M. (2012). CDK2-dependent activation of PARP-1 is required for hormonal gene regulation in breast cancer cells. Genes Dev. 26, 1972-83.

Wright, R.H., Lioutas, A., Le Dily, F., Soronellas, D., Pohl, A., Bonet, J., Nacht, A.S., Samino, S., Font-Mateu, J., Vicent, G.P., et al. (2016). ADP-ribose-derived nuclear ATP synthesis by NUDIX5 is required for chromatin remodeling. Science. 352, 1221-1225.

Yao, Y., Minor, P.J., Zhao, Y.-T., Jeong, Y., Pani, A.M., King, A.N., Symmons, O., Gan, L., Cardoso, W. V, Spitz, F., et al. (2016). Cis-regulatory architecture of a brain signaling center predates the origin of chordates. Nat. Genet. 48, 575-580.

Yin, J., Wang, G., Adelman, K., Lis, J.T., Akoulitchev, S., Chuikov, S., Reinberg, D., Apostolou, E., Ferrari, F., Walsh, R.M., et al. (2014). The Mediator complex: a master coordinator of transcription and cell lineage development. Development 141, 977-987.

Ying, Q.-L., Stavridis, M., Griffiths, D., Li, M., and Smith, A. (2003). Conversion of embryonic stem cells into neuroectodermal precursors in adherent monoculture. Nat. Biotechnol. 21, 183-186.

Zhang, F., Cong, L., Lodato, S., Kosuri, S., Church, G.M., and Arlotta, P. (2011). Efficient construction of sequence-specific TAL effectors for modulating mammalian transcription. Nat. Biotechnol. 29, 149-153.

Zhao, H., and Dean, A. (2004). An insulator blocks spreading of histone acetylation and interferes with RNA polymerase II transfer between an enhancer and gene. Nucleic Acids Res. 32, 4903-4919.

Zhu, X., Ling, J., Zhang, L., Pi, W., Wu, M., and Tuan, D. (2007). A facilitated tracking and transcription mechanism of long-range enhancer function. Nucleic Acids Res. 35, 5532-5544. 